\title{
Haptic-enabled virtual planning and assessment of product assembly
}

\begin{abstract}
Purpose - To present a new haptic-enabled virtual assembly system for the automatic generation and objective assessment of assembly plans. The system is intended to be used as an assembly planning tool along the product development process.

Design/methodology - The generation of product assembly plans is based on the analysis of the assembly movements and operations performed by the user during the virtual assembly execution, and the objective assessment of product assembly is based on the definition and computation of new proposed assembly metrics.

Finding - To evaluate the system, a case study corresponding to the assembly of a mechanical component is presented and analysed. The results demonstrate that the proposed system is an effective tool to plan and evaluate different product assembly strategies in a more practical and objective approach than existing assembly planning methods.
\end{abstract}

Research limitations - Although the virtual assembly execution time is larger than the real assembly execution time, the assembly planning and evaluation results provided by the system are valid. However, the development of higher performance collision detection algorithms is needed to reduce the simulation time.

Originality - The proposed virtual assembly system is able not only to simulate and automatically generate assembly plans, but also to objectively assess them from the virtual assembly task execution. The introduction and use of several assembly performance metrics to objectively evaluate assembly strategies in virtual assembly, also represents a novel contribution. 
Keywords - Virtual assembly (VA); haptics; virtual assembly planning; product assembly; assembly metrics.

\section{Article classification: Research paper}

\section{Introduction}

Assembly process planning plays a vital role in a new or remanufactured product because it affects its quality, manufacturing cost, production time and service life. In addition, the demand for service products, re-manufacturing and recycling has forced companies to consider the ease of product assembly and disassembly at the design stage. A good assembly plan can increase the efficiency of the manufacturing process and the quality of the product. According to the literature, the assembly process takes up to $50 \%$ of the total production time, and more than $20 \%$ of the total product manufacturing cost (De Fazio et al., 1991; Boothroyd and Alting, 1992). Because of this great impact on the manufacturing cost, a large number of research works have focused on enhancing the assembly planning process.

Traditional methods for assembly planning and evaluation, although effective, they are time consuming and costly because they depend on the specialist's experience, the physical prototypes and the measurement equipment (Liu et al., 2015). To accelerate the assembly planning process, Computer Aided Process Planning (CAPP) systems and mathematical algorithms have been developed; however, their results have not been successful (Thornton, 2009). One of the main reasons for this lack of success is that assembly planning depends on a high level of expertise, which has proved to be difficult to capture and formalise (Fletcher et al., 2012). Other disadvantages of these assembly planning methods include the lack of the usability required by industry; they are not intuitive and require significant training due to complex user interfaces and system's inflexibility, and the results are not always feasible and optimal (Thornton, 2009). 
Recently, Virtual Assembly (VA) technologies have emerged as a tool for planning and evaluating product assembly (Li et al., 2016; Garbaya et al., 2019). VA systems are based on the simulation of real assembly operations in an intuitive and interactive virtual environment that supports the human's assembly cognition, intuitiveness and ergonomic capabilities (Yusof and Latif, 2013). In addition, VA systems have been enhanced with haptic technologies to allow the natural manipulation and dynamic perception of virtual objects (Garbaya and Zaldivar, 2007; Gonzalez-Badillo et al., 2014).

Although VA systems and haptic technologies have advanced computational tools for assembly planning, they have failed in providing a practical solution to generate and evaluate assembly strategies. Most VA systems have focused on evaluating the feasibility of performing assembly tasks in a virtual environment, and little research effort has been made to generate practical and useful assembly information to assist the decision-making process along the product life cycle.

In this paper a novel haptic-enabled virtual assembly system for the automatic generation and objective assessment of assembly plans is proposed. The system is able to automatically generate assembly plans based on the automatic logging and analysis of the VA task execution. Assembly performance metrics are defined and computed to objectively evaluate the assembly strategies and to generate valuable assembly information.

\section{Related work}

Assembly planning is an important activity that comprises the analysis and simulation of the assembly operations and strategies required to produce a component. The aim of assembly planning is to feedback the product design process, and to identify the assembly strategy that leads to a more efficient and profitable product fabrication process. 
According to Homem de Mello and Sanderson (1991), the most important technical issues addressed in automated assembly planning are: assembly sequence representation, generation and evaluation; planning process accuracy and efficiency; CAD program integration; and task and motion planner integration.

Traditional methods for representing assembly plans have been summarized in the literature (Medellin et al., 2010; Wang et al., 2013) and they compromise: list of tasks, graph of connections, AND/OR graphs, directed graphs, non-directional blocking graph (NDBG), assembly trees, precedence graphs, Petri nets, and Liasion diagrams. On the other hand, assembly plan generation has primarily focused on algorithms for the fast and efficient generation of feasible assembly plans. However, as the number of parts in a product increases, the number of assembly plans increases exponentially, and therefore the generation and detection of a feasible and optimal assembly plan becomes a challenging task. Assembly plan generation methods can be classified into the following categories (Medellin et al., 2010): feasibility decomposition, forming subassemblies, precedence knowledge, graphical approach, genetic search, random approach, assembly state codification, grouping components, motion based, and virtual approaches.

Several methods for assembly planning have been proposed in the literature, such as genetic algorithms (Bonneville et al., 1995; Marian et al., 2006), simulated annealing (Hui et al., 2006), ant colony algorithms (Akpinar et al., 2013), particle swarm optimization (Lv et al., 2010), neural networks (Sinanoglu et al., 2005), petri net methods (Ben-Arieh et al., 2004; $\mathrm{Hu}$ and Liu, 2015; Chen and Hu, 2018, Yang and $\mathrm{Hu}, 2018$ ), among others. Although all these soft computing methods are capable of obtaining an optimal feasible assembly sequence, they have several limitations such as high computational time and local search space. Moreover, these algorithms do not consider all output parameters and hence the solution obtained is near the optimal. For these 
reasons, and despite all the research efforts, industrial assembly planning still relies on CAD software and the experience and knowledge of an expert.

Assembly evaluation aims to assess assembly plans in order to select the best feasible plan. Assembly feasibility involves manipulability, accessibility, stability, visibility, and geometrical, mechanical and material constraints evaluation. Traditional assembly evaluation relies on the fabrication of physical prototypes that are built and assembled by the specialist to identify any issues regarding the product design and assembly. However, as the assembly task gets more complex, such method tends to be time consuming, costly and prone to errors (Seth et al., 2011). In addition, assembly evaluation requires the definition of criteria to analyse and compare the different assembly plans (Goldwasser et $a l ., 1999)$. The evaluation criteria should consider performance parameters such as tool changes, part orientation changes, assembly complexity, assembly time, similar assembly operations, cost, ergonomics, energy consumption and parallelism.

In recent years, virtual assembly (VA) has become a popular assembly tool that can be defined as (Xia et al., 2013): The use of virtual reality, computer graphics, artificial intelligence technologies to construct a virtual model and environment of a product assembly in order to interactively analyse and simulate the product design and the assembly process. Several VA platforms have been proposed in the literature, but they have mainly focused on evaluating their functionality as a simulation tool rather than an engineering assisting tool. To address this problem, several authors have developed VA systems using different methodologies and features (Gonzalez-Badillo et al., 2014; Li et al., 2016; Garbaya et al., 2019). Table 1 summarizes the VA systems that have considered the analysis of the assembly process beyond simply bringing the parts together. In this table the systems have been dived into two main categories: haptic-enabled and hapticunabled systems. In addition, four main characteristics are identified: system evaluation, 
which refers to the evaluation of the system's functionality; sequence generation, which represents the ability of the system to generate assembly sequences; assembly metrics, which denotes the metrics or parameters used by the system; and assembly planning, which refers to the system's ability to generate, represent and evaluate assembly plans.

Table 1. VA systems for assembly planning.

\begin{tabular}{|c|c|c|c|c|c|c|c|c|c|c|}
\hline & \multirow[b]{2}{*}{ VA system } & \multirow[b]{2}{*}{$\begin{array}{c}\text { System } \\
\text { evaluation }\end{array}$} & \multirow[b]{2}{*}{$\begin{array}{l}\text { Sequence } \\
\text { generation }\end{array}$} & \multicolumn{4}{|c|}{ Assembly metrics } & \multicolumn{3}{|c|}{ Assembly planning } \\
\hline & & & & 已 & $\stackrel{5}{\varrho}$ & 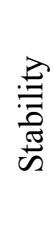 & 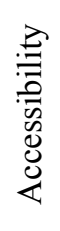 & 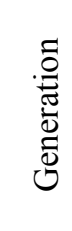 & 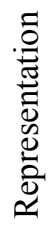 & 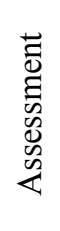 \\
\hline \multirow{12}{*}{ 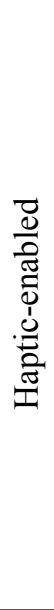 } & Xia et al., 2011 & $\mathrm{x}$ & & $\mathrm{x}$ & & & $\mathrm{x}$ & & & \\
\hline & Thing et al., 2010 & $\mathrm{x}$ & & $\mathrm{X}$ & & & $\mathrm{X}$ & & & \\
\hline & Bordegoni et al., 2009 & $\mathrm{x}$ & & $\mathrm{x}$ & & & $\mathrm{x}$ & & & \\
\hline & Vo et al., 2009 & $\mathrm{x}$ & & $\mathrm{X}$ & & & $\mathrm{x}$ & & & \\
\hline & Garbaya et al., 2007 & $\mathrm{x}$ & & $\mathrm{x}$ & & & $\mathrm{x}$ & & & \\
\hline & Adams et al., 2001 & $\mathrm{x}$ & & $\mathrm{x}$ & & & $\mathrm{x}$ & & & \\
\hline & Yoo, 2011 & $\mathrm{x}$ & & $\mathrm{x}$ & $\mathrm{x}$ & & $\mathrm{x}$ & & & $\mathrm{x}^{1}$ \\
\hline & Seth et al., 2006 & $\mathrm{x}$ & & $\mathrm{x}$ & & & $\mathrm{x}$ & & & $\mathrm{x}^{2}$ \\
\hline & Jia et al., 2009 & $\mathrm{x}$ & & $\mathrm{x}$ & & & $\mathrm{x}$ & & & \\
\hline & Ladeveze et al., 2010 & $\mathrm{x}$ & & $\mathrm{x}$ & & & $\mathrm{x}$ & & & \\
\hline & Hassan et al., 2010 & $\mathrm{x}$ & & & & & $\mathrm{x}$ & & & $x^{3}$ \\
\hline & Gonzalez et al., 2014 & $\mathrm{x}$ & $\mathrm{x}$ & $\mathrm{x}$ & & $\mathrm{x}$ & $\mathrm{x}$ & $\mathrm{x}$ & $\mathrm{x}$ & \\
\hline \multirow{8}{*}{ 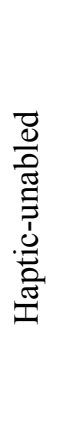 } & Boud et al., 2000 & $\mathrm{x}$ & & $\mathrm{x}$ & & & $\mathrm{x}$ & & & \\
\hline & Brough et al., 2007 & $\mathrm{x}$ & & $\mathrm{x}$ & & & & & & \\
\hline & Jayaram et al., 2007 & $\mathrm{x}$ & $\mathrm{x}$ & & & & & & & \\
\hline & Aleotti et al., 2011 & $\mathrm{x}$ & & $\mathrm{x}$ & & $\mathrm{x}$ & $\mathrm{x}$ & & & \\
\hline & Gao et al., 2014 & $\mathrm{x}$ & & $\mathrm{x}$ & $\mathrm{x}$ & $\mathrm{x}$ & $\mathrm{x}$ & & & \\
\hline & Li et al., 2016 & $\mathrm{x}$ & $\mathrm{x}$ & & & & $\mathrm{x}$ & & & \\
\hline & Garbaya et al., 2019 & $\mathrm{x}$ & $\mathrm{x}$ & & & & & $\mathrm{x}$ & & \\
\hline & $\begin{array}{l}\text { Jayasekera \& Xu, } \\
2019\end{array}$ & $\mathrm{x}$ & & & $\mathrm{x}$ & & $\mathrm{x}$ & & & \\
\hline
\end{tabular}

${ }^{1}$ 2-D Virtual environment, ${ }^{2}$ Only mentioned, ${ }^{3}$ In collaboration with Ant colony algorithm, TCT Assembly Task Completion Time, DOF Degrees of Freedom

From Table 1 it is observed that the VA planning systems reported in the literature have been evaluated in terms of its functionality and ability to simulate assembly tasks, but only two are able to generate the assembly sequence from the virtual assembly execution. 
The assembly task completion time (TCT) and the accessibility are the assembly metrics used in most of the systems. Only two systems are able to analyse the assembly stability. Regarding the assembly planning, only one system can generate and represent assembly plans, and very few systems perform limited evaluations of virtual assembly strategies. Thus, it can be said that although there have been several VA systems reported in the literature, most of them have focused on evaluating the feasibility of performing assembly tasks rather than on the generation of practical and optimal assembly plans. Consequently, existing VA systems can simulate product assembly tasks but they cannot perform analyses and assessments to generate useful assembly data to support the decision-making process.

\section{System description}

The proposed haptic-enabled VA planning and assessment approach incorporates the physical-based behaviour and collision detection into the virtual environment to generate only feasible assembly plans, similar as in the real world. Moreover, human expertise and knowledge is incorporated into the VA planning process. Therefore, feasible assembly sequences near to the optimal solution are generated as shown in Figure 1. In this way, the computational cost and time are reduced, and the planning process becomes more efficient and practical than when using existing algorithms. 


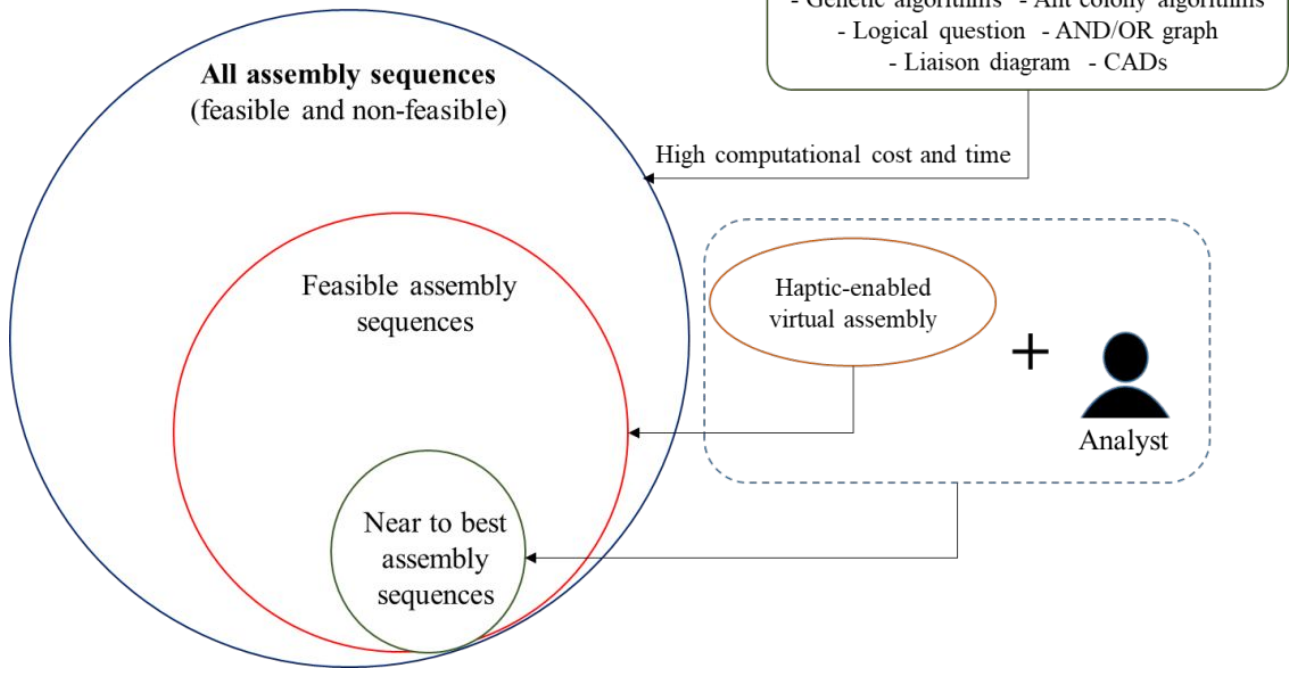

Figure 1. Haptic-enabled VA planning vs. other assembly planning methods.

The new proposed haptic-enabled VA approach has been implemented in the Haptic Assembly and Manufacturing System (HAMS) (Gallegos et al., 2017). The extended architecture of HAMS is shown in Figure 2 and comprises five modules:

1. Input module. Enables the importing and uploading of virtual models into the system (*.stl, *.obj, *.vtk), and the definition of the model properties.

2. Graphics module. Responsible of the graphics rendering, which includes the virtual scene and 3D models; the visualization of assembly paths, messages and assembly information; and the creation of buttons and widgets to configure the simulation parameters.

3. Physics module. Enables the physical-based behaviour of virtual objects in order to have realistic dynamic and collision responses.

4. Haptic module. Provides force feedback to the user to enable the sense of touch and kinesthesia. 
5. Planning module. Responsible of the assembly data logging, the analysis of the assembly movements, the generation of assembly plans and assembly metrics, and the assessment of assembly plans.

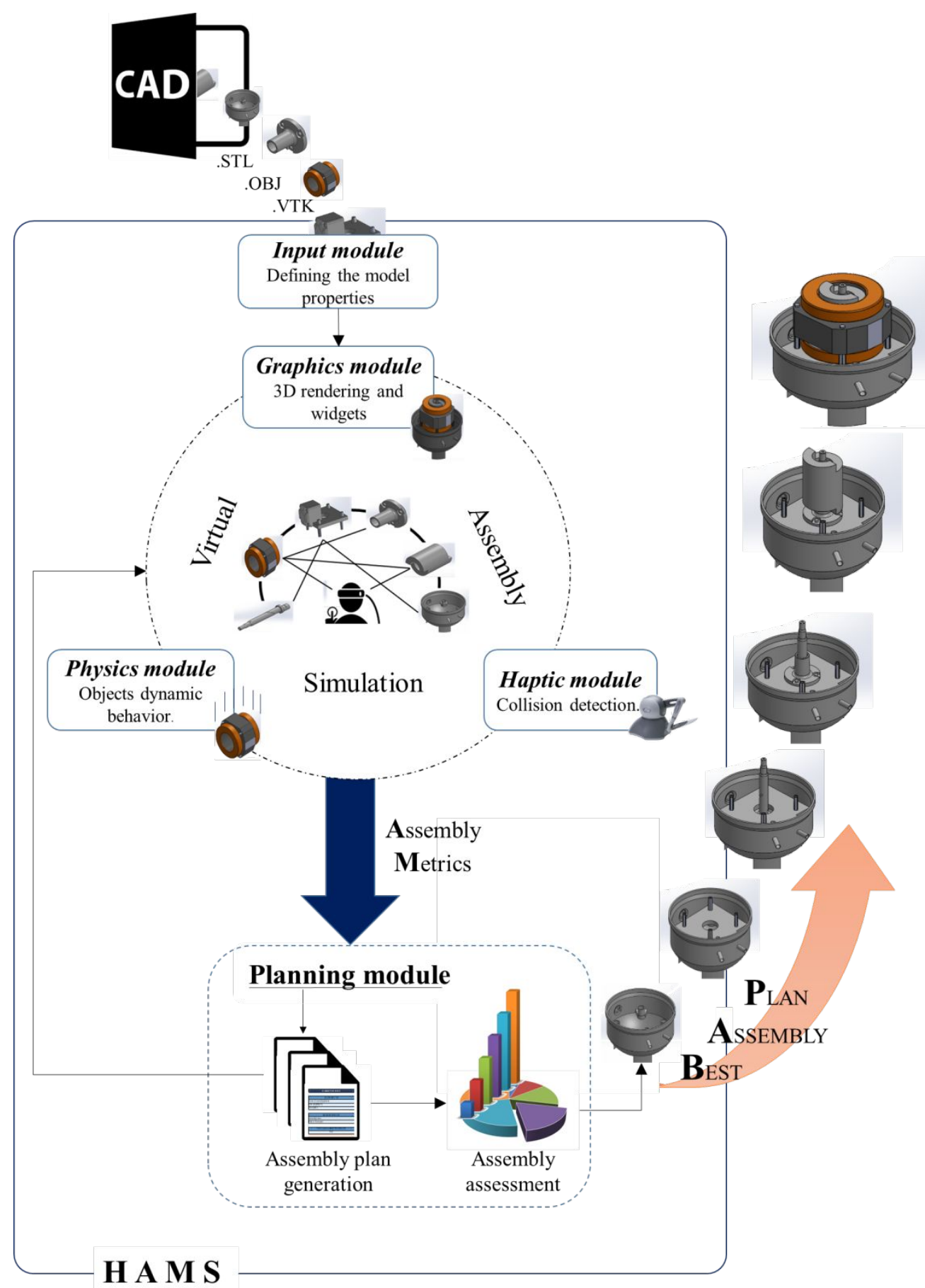

Figure 2. HAMS architecture. 
The HAMS system has been implemented in Visual studio $\mathrm{C}++$ using the Microsoft Foundation Class (MFC); the Visualization Tool Kit libraries (VTK 5.10) for the graphic rendering of the virtual environment; the physics simulation engines Bullet, PhysX v2.8 and PhysX v3.1; and the Open Haptics v3.0 to enable the haptic feedback by means of the Phantom Omni device from Sensable ${ }^{\circledR}$.

The main functionalities of HAMS are haptic-enabled free manipulation of virtual objects, dynamic behaviour and collision detection of virtual objects, automatic assembly data logging (position, movements, time, etc.), automatic computation of assembly metrics, automatic generation of assembly plans from virtual assembly execution, and objective assessment of assembly plans.

\section{Assembly planning}

Figure 3 presents the overall procedure of the assembly planning module, which comprises two main tasks: assembly plan generation and assembly plan assessment. 


\subsection{Assembly plan generation}

\subsubsection{Assembly parameters}

Before starting the VA execution, it is necessary to define the following parameters for the calculation of the assembly metrics: 
- Friction factors $\left(f_{x}, f_{y}, f_{z}\right)$, to estimate the friction work required to move a part along the $\mathrm{X}, \mathrm{Y}$, or $\mathrm{Z}$ directions, respectively.

- Resolution $(r)$, to define the resolution of the VA trajectories.

- Time-scale $\left(n_{t}\right)$, to estimate the real assembly times from the corresponding VA times:

$$
n_{t}=T C T_{\text {virtual }} / T C T_{\text {real }}
$$

From previous studies in HAMS, $n_{t}$ has an average value of $17.7 \pm 2$ (Gallegos et al., 2017).

- Sound, to enable or disable a real-life industry audio during the VA execution.

\subsubsection{Virtual assembly task execution}

After an assembly task has been uploaded into the system, the user can freely interact with the virtual objects by means of the haptic device, and perform the product assembly. During the VA execution, the system provides the user with the sense of touch to explore and manipulate virtual objects. The user can feel dynamic forces such as weight, inertia and collision among the virtual objects. The system tracks and logs all the information regarding the assembly sequence, trajectories and movements (positions, timestamps, speeds, etc.) made by the user during the VA execution.

\subsubsection{Assembly metrics}

To objectively assess assembly plans, several assembly metrics are proposed and automatically computed by the system. The proposed metrics are subdivided into part metrics and product metrics. Part metrics refer to the assembly values corresponding to each individual part, whereas product metrics refer to the assembly values corresponding to the complete product assembly task. The proposed metrics are defined as follows: 
- Part handling $(\boldsymbol{P H})$. Refers to the number of times a part is handled by the user.

- Effective handling time $(\boldsymbol{E H T})$. Time duration from the grasping to the release of a part. If a part is manipulated more than once, the time is accumulated.

- Non-productive handling time (NPHT). Time duration from the release of the previous part to the grasping of the next part.

- Effective handling distance (EHD). Travelled distance from the grasping to the release of a part. If a part is manipulated more than once, the distance is accumulated.

- Non-productive handling distance (NPHD). Travelled distance from the release of previous part to the grasping of the next part.

- Start point $(\boldsymbol{S P})$. Initial position $(x, y, z)$ of the part.

- Final point (FP). Final position $(x, y, z)$ of the part.

- Final orientation $(\boldsymbol{F O})$. Final orientation $(\theta x, \theta y, \theta z)$ of the part.

Figure 4 illustrates the concepts of $E H D$ and $N P H D$, whereas Figure 5 illustrates the concepts of $S P, F P$ and $F O$.

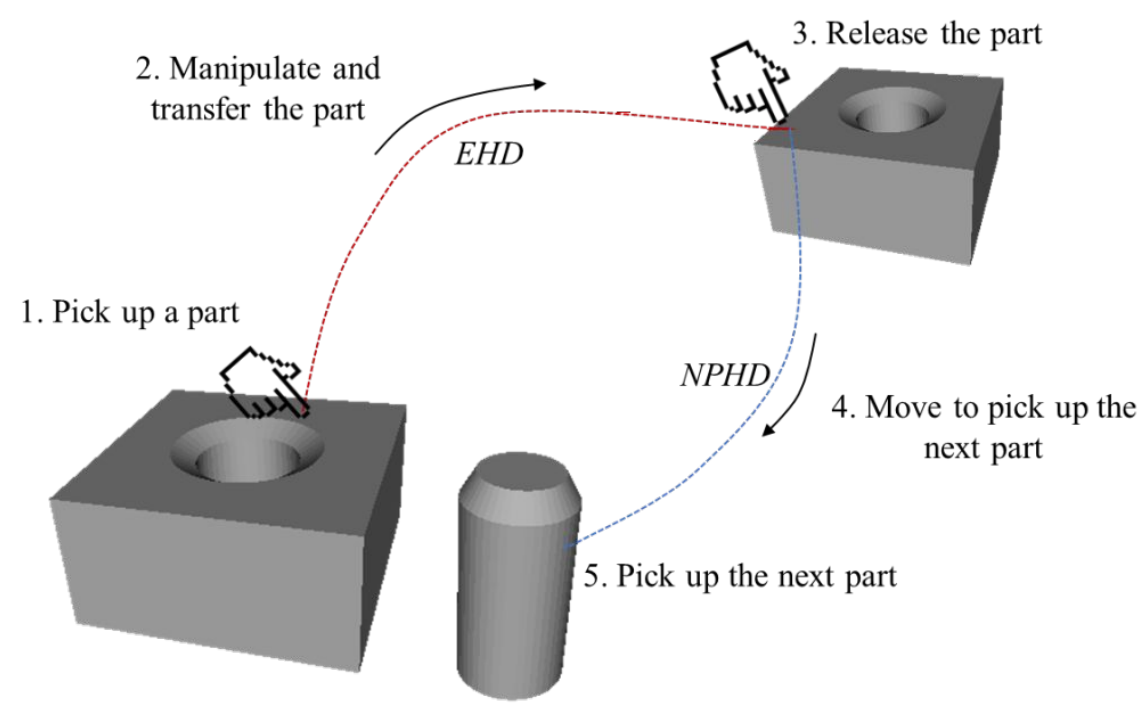

Figure 4. Distance concepts involved in the VA. 


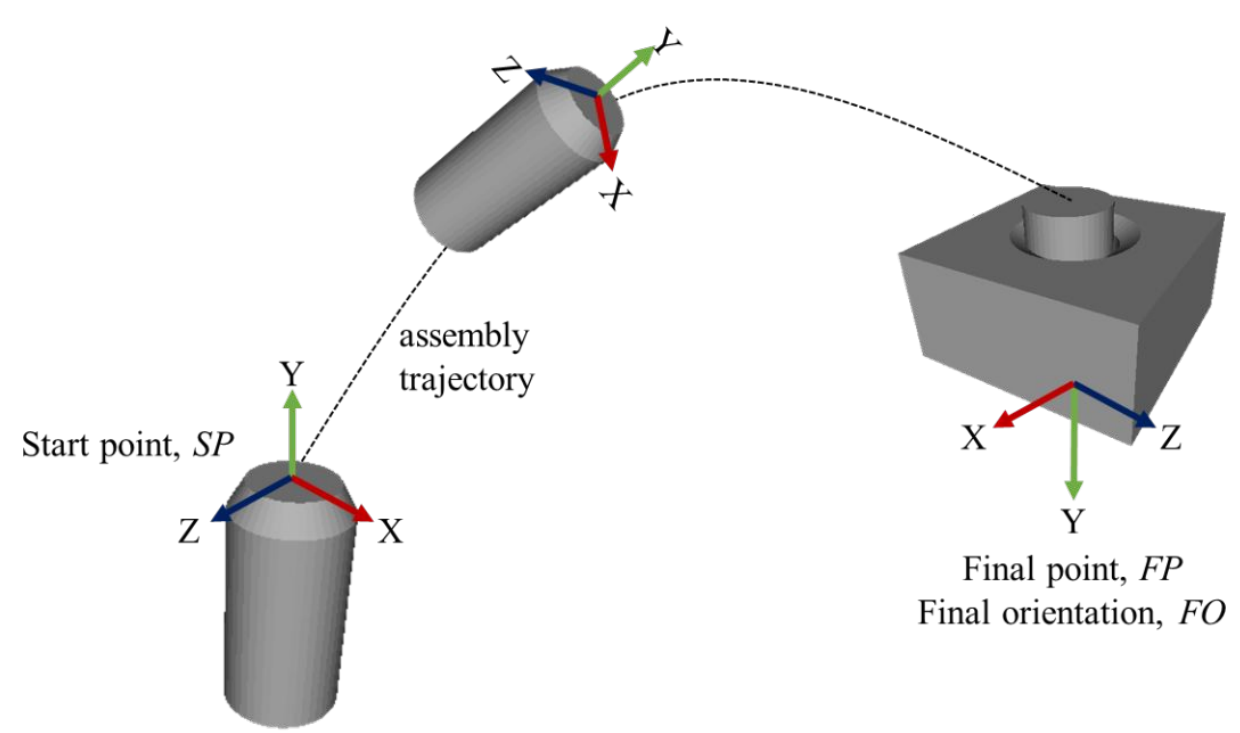

Figure 5. Initial and final configuration of a part.

- Potential energy (PE). Potential energy required to manipulate a part along the assembly trajectory:

$$
P E=m g\left(y_{\max }-y_{\min }\right)
$$

where $m$ is the mass of the part, $g$ is the gravity, and $y_{\max }$ and $y_{\min }$ are the maximum and minimum elevations along the assembly trajectory.

- Effective potential energy (EPE). Potential energy change between the initial and the final position of a part:

$$
E P E=m g\left(y_{\text {final }}-y_{\text {initial }}\right)
$$

where $y_{\text {initial }}$ and and $y_{\text {final }}$ are the initial and final elevations of the part.

- Potential energy efficiency $(P E E)$. It is defined as:

$$
P E E=E P E / P E
$$

- Total energy $(\boldsymbol{T E})$. Total work or energy required to move a part along its assembly trajectory. The total energy is estimated based on the principle of virtual work as follows:

$$
T E=m g \sum\left[\Delta_{x} f_{x}+\Delta_{y} f_{y}+\Delta_{z} f_{z}+\left(\Delta_{y} \text { if } \Delta_{y}>0\right)\right]
$$


where $\Delta_{x}, \Delta_{y}$, and $\Delta_{z}$ are the small displacements and $f_{x}, f_{y}, f_{z}$ are the friction factors of the part along the $\mathrm{X}, \mathrm{Y}$ and $\mathrm{Z}$ directions, respectively.

- Total energy efficiency (TEE). It is defined as:

$$
T E E=E P E / T E
$$

Figure 6 shows the assembly trajectory of a part, which comprises all the small displacements $\left(\Delta_{x}, \Delta_{y}, \Delta_{z}\right)$ corresponding to each simulation cycle. On the other hand, Figure 7 illustrates the $P E, E P E$ and $T E$ concepts.

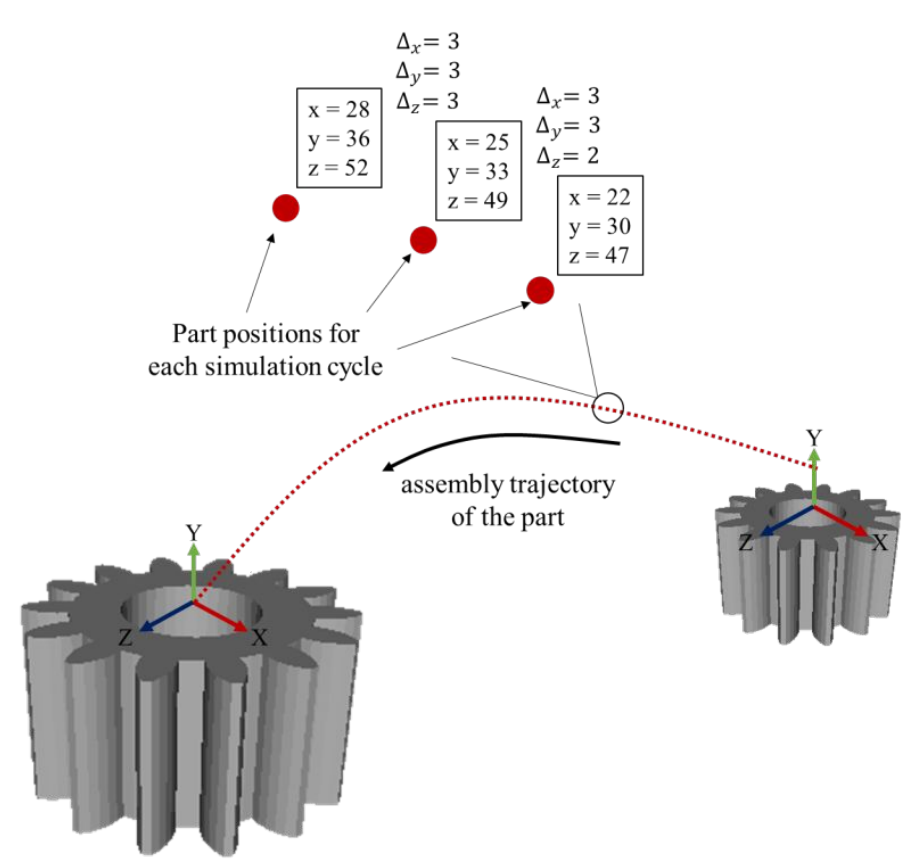

Figure 6. Displacements comprising a virtual assembly path. 


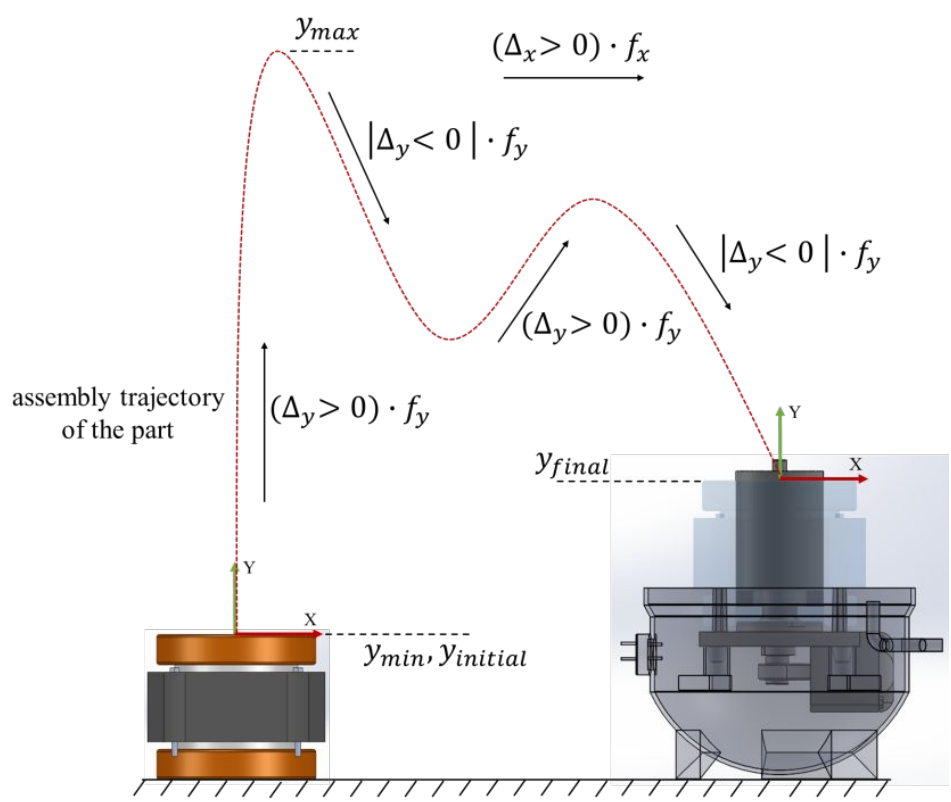

Figure 7. Energy concepts when moving a part.

- Effective task completion time (ETCT). Sum of all the $E H T$ values corresponding to the $n$ parts of a product:

$$
E T C T=\sum_{i=1}^{n} E H T
$$

- Non-productive task completion time (NPTCT). Sum of all the NPHT values corresponding to the $n$ parts of a product:

$$
N P T C T=\sum_{i=1}^{n} N P H T
$$

- Task completion time (TCT). Total time to complete the product assembly:

$$
T C T=E T C T+N P T C T
$$

- Effective assembly distance $(\boldsymbol{E A D})$. Total distance travelled when moving parts during the VA execution:

$$
E A D=\sum_{i=1}^{n} E H D
$$

- Non-productive assembly distance (NPAD). Total travelled distance when no parts are moved during the VA execution:

$$
N P A D=\sum_{i=1}^{n} N P H D
$$


- Total assembly distance $(T A D)$. Total travelled distance during the execution of the product assembly:

$$
T A D=E A D+N P A D
$$

- Total assembly energy $(\boldsymbol{T A E})$. Total work or energy required to complete the product assembly:

$$
T A E=\sum_{i=1}^{n} T E
$$

- Total assembly energy efficiency (TAEE). Energy efficiency of the entire assembly process:

$$
T A E E=\sum_{i=1}^{n} E P E / \sum_{i=1}^{n} T E
$$

- Assembly potential energy efficiency $(\boldsymbol{A P E E})$. Efficiency of the assembly process in terms of the potential energy:

$$
A P E E=\sum_{i=1}^{n} E P E / \sum_{i=1}^{n} P E
$$

- Workspace (WS). Size of the workspace required to carry out the product assembly. The workspace is represented by a rectangular prism with dimensions $(d x, d y, d z)$ that bounds all the assembly trajectories, as shown in Figure 8.

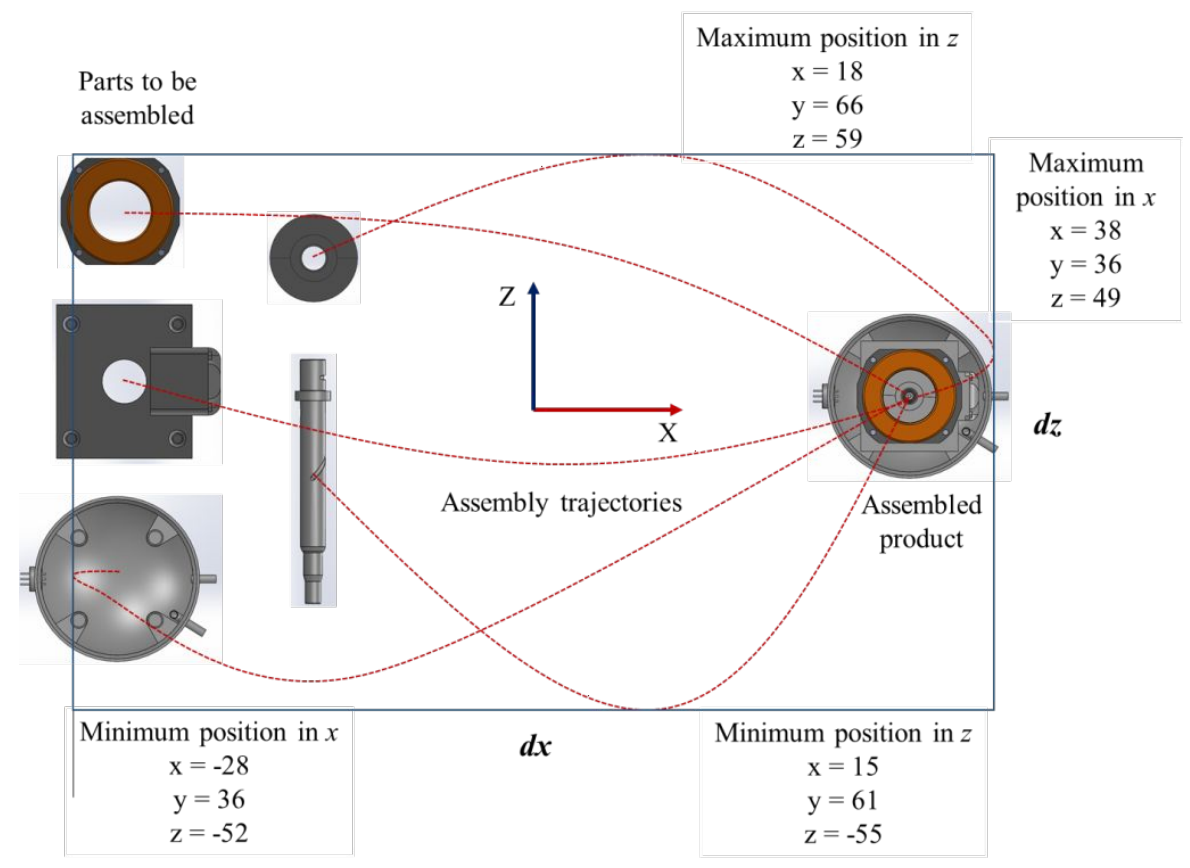


Figure 8. Representation of the virtual workspace.

- Assembly manipulability $(\boldsymbol{A M})$. It is defined as the degree of angular dexterity or manipulability required to carry out the assembly task. It is quantified as the maximum required angular amplitude of rotation around each axis $(d \theta x, d \theta y, d \theta z)$ during the VA execution (yaw, pitch and roll rotations), as shown in Figure 9.

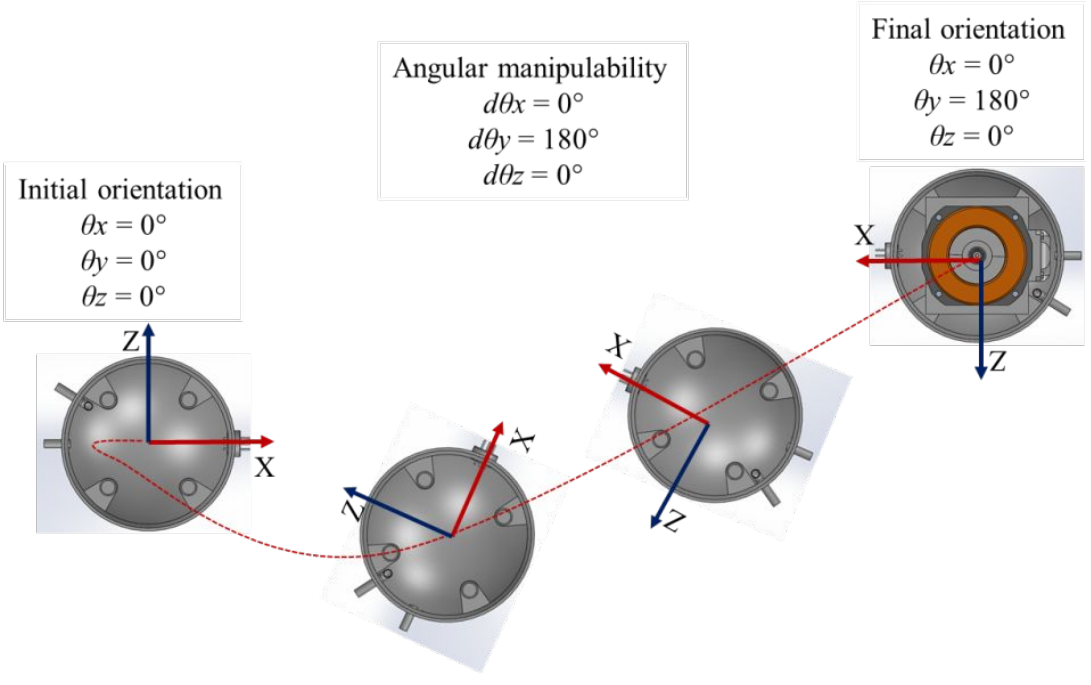

Figure 9. Representation of the assembly manipulability concept.

- Degrees of freedom $(\boldsymbol{D O F})$. Degrees of freedom used to perform the virtual assembly.

- Total assembly handling $(\boldsymbol{T A H})$. Total number of times that all parts were manipulated (grasped) during the product assembly execution:

$$
T A H=\sum_{i=1}^{n} P H
$$

- Handling efficiency $(\boldsymbol{H E})$. Efficiency of the manipulation or grasping operation. It is defined as the ratio between the number of parts $(n)$ and the $T A H$, as follows:

$$
H E=n / T A H
$$

\subsubsection{Assembly plan}


An assembly plan is automatically generated by the system after the user concludes the product assembly. This plan is saved automatically as an *.cvs file and comprises the job information, the model information, the part assembly metrics and the task assembly metrics.

\subsection{Assembly plan assessment}

After several assembly plans have been generated, they are analysed and evaluated to identify the best assembly plan. The GUI of the assessment analysis comprises six sections, as shown in Figure 10:

1. Name. Analyst's name.

2. Evaluation criteria. Shows the assembly metrics for the user to select one or more as evaluation criteria, and to define priorities.

3. Select the plans. Allows the selection of the assembly plans to be evaluated.

4. Summary. Presents the results of the assembly assessment, ordered from the best to the worst plan according to the selected criteria and priorities.

5. Chart. Compares the assembly plans at a glance by means of a bar chart.

6. Additional information. Allows saving the assessment results.

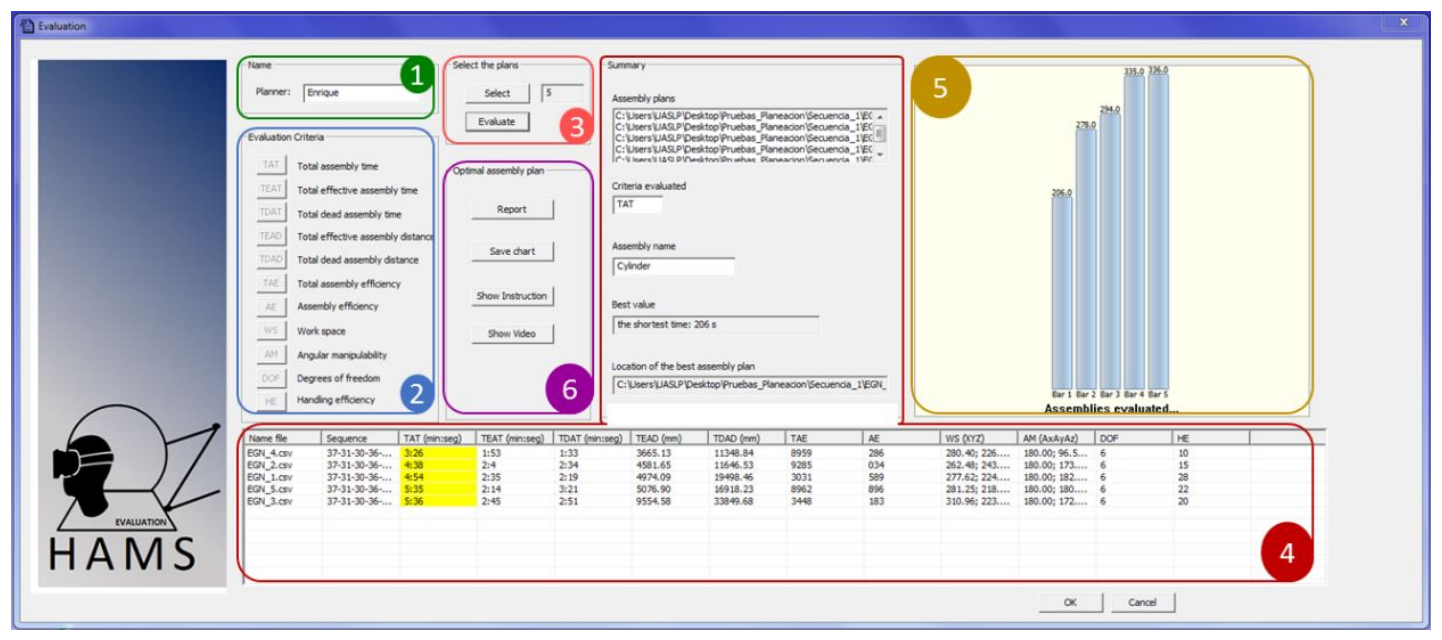

Figure 10. Assembly plan assessment GUI. 


\section{Case study}

\subsection{Description}

To evaluate the functionality of the proposed approach a case study corresponding to a linear actuator was selected as shown in Figure 11. According to the number of parts, this device has 40,320 different assembly sequences (feasible and non-feasible). However, because of the dynamic behaviour and collision detection of virtual objects in HAMS, all non-feasible assembly sequences stay automatically out of the analysis. As an example, Figure 12 shows two non-feasible assembly sequences due to accessibility and stability problems.

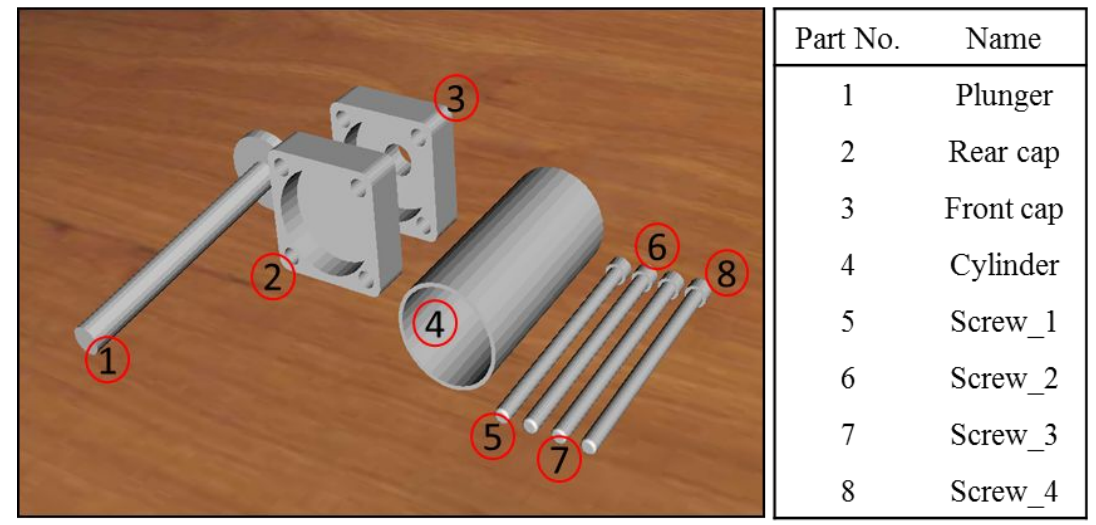

Figure 11. Linear actuator virtual assembly task loaded into HAMS.

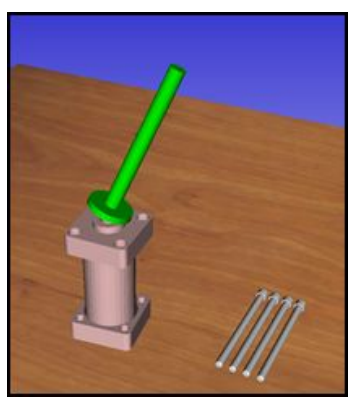

(a)

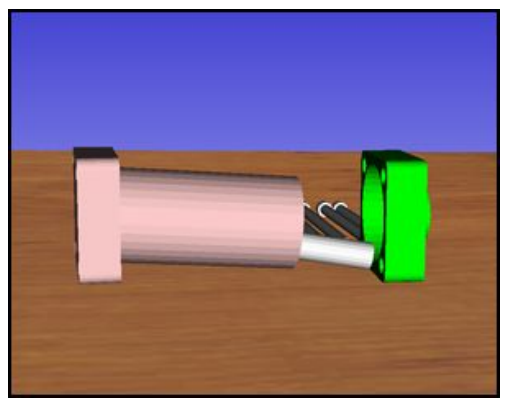

(b)

Figure 12. Non-feasible assembly sequences: a) accessibility problem and b) stability problem. 
After some preliminary tests in HAMS, the following two feasible assembly sequences were selected by the assembly specialist:

- Assembly sequence $1(\mathrm{AS} 1)$ : $\{2-4-1-3-5-6-7-8\}$

- Assembly sequence 2(AS2): $\{2-1-4-3-5-6-7-8\}$

Although there are more feasible assembly sequences, such as $\{2-4-1-3-6-5-7$ $-8\},\{2-4-1-3-5-8-7-6\}$, etc., the assembly specialist decided that the two selected sequences were closer to the optimal sequence than the others.

\subsection{Assembly plans}

The product assembly was executed by the specialist using the two selected assembly strategies. Table 2 and Table 3 present the part and the product assembly metrics, respectively. Figure 13 shows the assembly instructions generated automatically by the system, which can be used in the real assembly process. 


\begin{tabular}{|c|c|c|c|c|c|c|c|c|c|c|c|c|c|c|c|c|c|c|}
\hline$\frac{5}{2}$ & & 0 & $\ddot{n}$ & 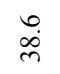 & if & $\frac{\vec{m}}{m}$ & बें & iे & $\stackrel{m}{\text { iे }}$ & & 0 & $\vec{i}$ & ì & $\stackrel{m}{i n}$ & $\begin{array}{l}\text { i. } \\
\text { jె }\end{array}$ & $\stackrel{m}{\stackrel{m}{m}}$ & $\begin{array}{l}n \\
\ddot{n} \\
m\end{array}$ & 官 \\
\hline $\mathbb{8}$ & & 0 & $\begin{array}{l}\vec{d} \\
\dot{q}\end{array}$ & $\stackrel{\vec{m}}{\dot{m}}$ & 苘 & $\stackrel{+}{\dot{m}}$ & $\stackrel{m}{=}$ & na & $\stackrel{\infty}{\stackrel{\sim}{\sim}}$ & & 0 & $\overrightarrow{5}$ & $\stackrel{\infty}{\stackrel{i}{~}}$ & ڤેे & on & $\stackrel{r}{m}$ & $\begin{array}{l}\infty \\
\stackrel{i}{m}\end{array}$ & $\begin{array}{l}\qquad \\
\stackrel{0}{a}\end{array}$ \\
\hline 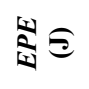 & & 0 & 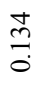 & ڤ̊ำ & 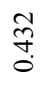 & 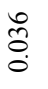 & $\ddot{\delta}$ & $\begin{array}{l}0 \\
\stackrel{0}{0} \\
0\end{array}$ & $\stackrel{+}{\stackrel{\sigma}{0}}$ & & $\circ$ & 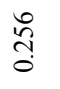 & $\begin{array}{l}\vec{\sigma} \\
0 \\
0\end{array}$ & 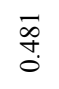 & 离 & ఫ̦ & 它 & $\begin{array}{l}\vec{s} \\
\dot{0}\end{array}$ \\
\hline$\triangleq \bigodot$ & & $\begin{array}{l}\infty \\
\vdots \\
0 \\
0\end{array}$ & ळ్ & 㕝 & $\begin{array}{l}\infty \\
\infty \\
\infty \\
0\end{array}$ & $\stackrel{ \pm}{=}$ & ¿ั่ & $\stackrel{\stackrel{0}{\mathcal{I}}}{\stackrel{0}{0}}$ & 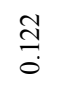 & & 品 & 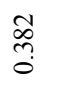 & 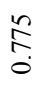 & $\stackrel{\substack{+\infty}}{\stackrel{-}{-}}$ & $\stackrel{n}{m}$ & $\begin{array}{l}0 \\
\stackrel{0}{0} \\
0\end{array}$ & 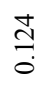 & 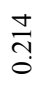 \\
\hline$\Xi$ & & ర్ర & त̂̀ & : & $\hat{\hat{o}}$ & $\begin{array}{l}\cong \\
\vdots \\
0\end{array}$ & $\stackrel{n}{=}$ & $\begin{array}{l}\stackrel{\text { Iิ }}{0} \\
0\end{array}$ & $\stackrel{\Xi}{=}$ & & $\stackrel{\infty}{\stackrel{0}{0}}$ & $\begin{array}{l}8 \\
\substack{n \\
0}\end{array}$ & مิ & $\underset{\infty}{\infty}$ & 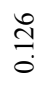 & 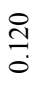 & $\stackrel{n}{=}$ & $\stackrel{0}{0}$ \\
\hline$\sigma^{D^{2}}$ & & 0 & 8 & $\stackrel{9}{1}$ & 0. & \& & $\stackrel{1}{1}$ & \& & \& & & 0 & \& & \& & 0 & å & ๑ & 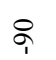 & \& \\
\hline$a^{D^{*}}$ & & 0 & $\begin{array}{l}0 \\
1 \\
0 \\
0\end{array}$ & $\begin{array}{l}0 \\
0 \\
0 \\
0\end{array}$ & $\begin{array}{l}0 \\
8\end{array}$ & $\begin{array}{l}0 \\
\vdots \\
0 \\
0\end{array}$ & $\begin{array}{l}0 \\
1 \\
0 \\
0\end{array}$ & $\begin{array}{l}0 \\
1 \\
0 \\
0\end{array}$ & $\begin{array}{l}8 \\
8 \\
0\end{array}$ & & : & $\begin{array}{l}0 \\
0 \\
0 \\
0\end{array}$ & $\begin{array}{l}0 \\
0 \\
0 \\
0\end{array}$ & $\begin{array}{l}\dot{0} \\
8\end{array}$ & $\begin{array}{l}0 \\
0 \\
0\end{array}$ & $\begin{array}{l}0 \\
0 \\
0\end{array}$ & $\begin{array}{l}0 \\
\vdots \\
0\end{array}$ & \& \\
\hline $\mathrm{E} \overline{\mathrm{N}}$ & $\overline{8}$ & in & in & in & in & $\cong$ & 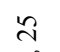 & $\stackrel{2}{2}$ & $\ddot{\imath}$ & $\tilde{8}$ & Ұ & $\stackrel{\infty}{+}$ & f & in & הิ & 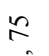 & i & ป \\
\hline $\begin{array}{ll}E \\
0\end{array}$ & $\bar{\Xi}$ & $=$ & 6 & के & さำ & $\begin{array}{l}8 \\
i\end{array}$ & $\begin{array}{l}2 \\
i\end{array}$ & $\begin{array}{l}\stackrel{8}{2} \\
\infty\end{array}$ & $\begin{array}{l}? \\
\infty \\
\infty\end{array}$ & $\stackrel{\Xi}{\Xi}$ & $\stackrel{2}{=}$ & $\dot{8}$ & $\stackrel{8}{\circ}$ & 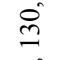 & 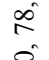 & $\stackrel{n}{n}$ & $\hat{i}$ & $\stackrel{\infty}{\stackrel{0}{\sim}}$ \\
\hline & $\begin{array}{l}\dot{J}^{\prime} \\
\dot{\omega}\end{array}$ & & & & & & & & & $\begin{array}{l}\dot{J}^{\prime} \\
\omega_{0}\end{array}$ & & & & & & & & \\
\hline$\widehat{\mathrm{E}}$ & $\overline{\mathbf{a}}$ & $\stackrel{\circ}{\circ}$ & $\begin{array}{l}0 \\
\therefore\end{array}$ & $\begin{array}{l}\text { y } \\
\text { so }\end{array}$ & ధ: & $\stackrel{+}{\dot{r}}$ & $\begin{array}{l}\dot{a} \\
\text { in }\end{array}$ & $\begin{array}{l}\vec{\nabla} \\
\dot{n}\end{array}$ & $\begin{array}{l}\vec{r} \\
\text { in }\end{array}$ & $\overline{\mathbf{B}}$ & $\stackrel{0}{\circ}$ & $\begin{array}{l}\text { İ } \\
\text { 6. }\end{array}$ & $\begin{array}{l}0 \\
i\end{array}$ & $\stackrel{8}{1}$ & $\stackrel{+}{n}$ & $\stackrel{+}{i}$ & $\begin{array}{l}\dot{0} \\
\text { in }\end{array}$ & it \\
\hline ธँ & 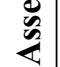 & $\hat{0}^{m}$ & $\stackrel{+}{\Xi}$ & $\overrightarrow{0}$ & $\begin{array}{l}\text { m } \\
0 \\
0\end{array}$ & 8 & $\hat{n}$ & $\dot{E}$ & $\stackrel{\infty}{=}$ & $\begin{array}{l}0 \\
0 \\
2 \\
2\end{array}$ & $\hat{0}_{0}^{m}$ & $\overrightarrow{0}$ & $\stackrel{+}{\Xi}$ & $\begin{array}{l}\text { f } \\
0 \\
0\end{array}$ & q & $\hat{n}$ & $\stackrel{8}{\Omega}$ & $\stackrel{\infty}{=}$ \\
\hline 令 & & 0 & fै & $\begin{array}{l}0 \\
\stackrel{i}{ } \\
\stackrel{\infty}{N}\end{array}$ & ت. & 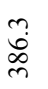 & $\begin{array}{l}n \\
\stackrel{n}{0} \\
\stackrel{n}{*}\end{array}$ & $\stackrel{n}{\tilde{m}}$ & $\stackrel{\infty}{\stackrel{\Delta}{\Delta}}$ & & 0 & तु & $\begin{array}{l}\tilde{a} \\
\stackrel{2}{a}\end{array}$ & $\begin{array}{l}n \\
n \\
0 \\
0\end{array}$ & $\begin{array}{l}\vec{i} \\
i\end{array}$ & $\stackrel{m}{\frac{m}{5}}$ & $\underset{\sim}{\tilde{n}}$ & $\begin{array}{l}\hat{\phi} \\
\text { ठ্ं }\end{array}$ \\
\hline 尽氞 & & $\hat{\check{n}}$ & $\vec{\sim}$ & $\underset{\stackrel{9}{q}}{\stackrel{q}{f}}$ & 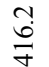 & 离 & 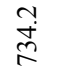 & $\begin{array}{l}\sqrt{3} \\
\frac{8}{6}\end{array}$ & 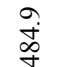 & & $\overrightarrow{\stackrel{\Im}{\beth}}$ & తి & 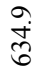 & $\begin{array}{l}0 \\
\text { ه. } \\
0\end{array}$ & $\vec{y}$ & ָొ & $\begin{array}{l}n \\
\infty \\
\infty \\
\end{array}$ & $\overrightarrow{\tilde{\sigma}}$ \\
\hline$\sqrt{0}$ & & 0 & $m$ & $\stackrel{\infty}{\sim}$ & ते & $\bar{m}$ & $\stackrel{\infty}{\sim}$ & $=$ & $\simeq$ & & 0 & $m$ & $\stackrel{\text { i }}{2}$ & $\stackrel{\circ}{n}$ & $\vec{\lambda}$ & 2 & $\tilde{d}$ & $=$ \\
\hline$\Xi 0$ & & $r$ & 2 & $\stackrel{\infty}{-}$ & के & $\stackrel{0}{\simeq}$ & 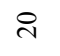 & n & 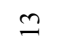 & & $\infty$ & 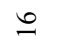 & f & $\vec{\nabla}$ & \pm & $=$ & $=$ & ल) \\
\hline$\Xi$ & & - & - & $m$ & $m$ & $m$ & $m$ & - & - & & - & - & r & $m$ & - & $m$ & - & m \\
\hline 营 & & 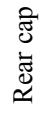 & 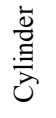 & $\begin{array}{l}\overline{\bar{\Delta}} \\
\stackrel{\Xi}{\Xi} \\
\bar{\Xi}\end{array}$ & 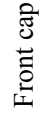 & 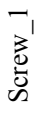 & 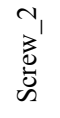 & $\begin{array}{l}m_{1} \\
z^{3} \\
\tilde{y}^{2} \\
n^{2}\end{array}$ & 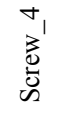 & & 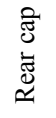 & $\begin{array}{l}\text { 总 } \\
\text { 恚 }\end{array}$ & 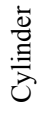 & 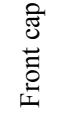 & $\begin{array}{l}\overrightarrow{1} \\
\overrightarrow{0} \\
\overrightarrow{0} \\
\tilde{n}\end{array}$ & $\begin{array}{l}N_{1} \\
\text { 童 } \\
\text { d. }\end{array}$ & 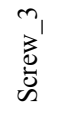 & 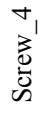 \\
\hline 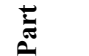 & & $\sim$ & $\nabla$ & - & $m$ & n & 0 & $r$ & $\infty$ & & $\sim$ & - & 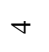 & $m$ & in & 6 & $r$ & $\infty$ \\
\hline
\end{tabular}


Table 3. Task assembly metrics.

\begin{tabular}{cll}
\hline Assembly metric & \multicolumn{1}{c}{ Assembly sequence 1 } & \multicolumn{1}{c}{ Assembly sequence 2 } \\
\hline$E T C T$ & $137 \mathrm{~s}$ & $180 \mathrm{~s}$ \\
$N P T C T$ & $154 \mathrm{~s}$ & $164 \mathrm{~s}$ \\
$T C T$ & $291 \mathrm{~s}$ & $344 \mathrm{~s}$ \\
$E A D$ & $3875 \mathrm{~mm}$ & $3966 \mathrm{~mm}$ \\
$N P A D$ & $7134 \mathrm{~mm}$ & $7254 \mathrm{~mm}$ \\
$T A D$ & $11009 \mathrm{~mm}$ & $11220 \mathrm{~mm}$ \\
$T A E$ & $2.485 \mathrm{~J}$ & $3.694 \mathrm{~J}$ \\
$T A E E$ & $38.75 \%$ & $28.8 \%$ \\
$A P E E$ & $43.04 \%$ & $43.08 \%$ \\
$W S$ & $(277.6,224.5,206.5) \mathrm{mm}$ & $(263.2,221.5,189.2) \mathrm{mm}$ \\
$A M$ & $\theta_{x}=180^{\circ}, \theta_{y}=180^{\circ}, \theta_{z}=180^{\circ}$ & $\theta_{x}=180^{\circ}, \theta_{y}=180^{\circ}, \theta_{z}=180^{\circ}$ \\
$D O F$ & 6 & 6 \\
$T A H$ & 16 & 20 \\
$H E$ & $50 \%$ & $40 \%$ \\
\hline
\end{tabular}

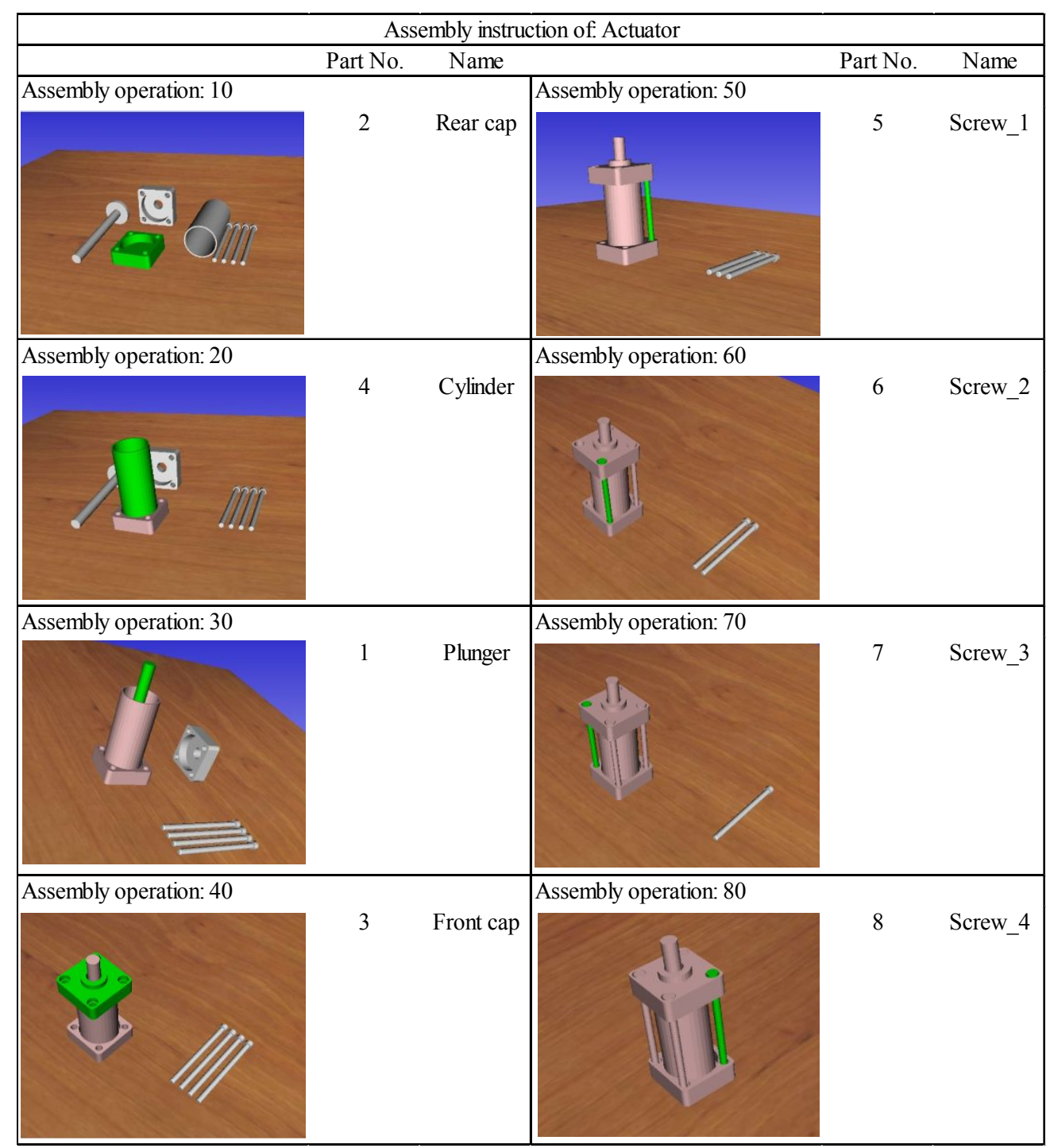


Figure 13. Assembly instructions corresponding to AS1.

\subsection{Assembly assessment}

In general, AS1 is the best assembly strategy because in most of the assembly metrics ( $>$ $70 \%$ ) it obtained better values than AS2. However, the selection of the best assembly plan may depend on the particular criterion defined by the specialist.

Regarding the assembly time performance, AS1 is the best because its $T C T$ value is $15 \%$ smaller than AS2. Moreover, in all time related assembly metrics (TCT, ETCT and NPTCT) AS1 leads to smaller values than AS2. In terms of time efficiency (ETCT/TCT), both assembly sequences have an efficiency of $50 \%$, but AS1 is faster than AS2. Considering a time scale factor of 17.7 (Gallegos et al., 2017), the expected TCT values in the real assembly process are 16.4 and 19.4 seconds for AS1 and AS2, respectively. Concerning the assembly travelled distance; the results show that AS1 requires a smaller travelled distance than AS2. The assembly distance efficiency $(E A D / T A D)$ is $36 \%$ for both sequences. Figure 14 shows some of the assembly trajectories corresponding to AS1.

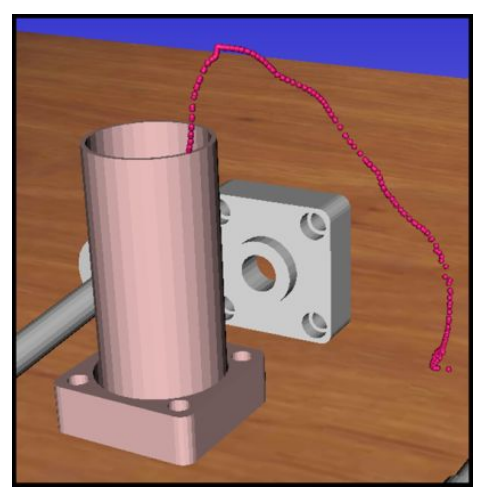

(a)

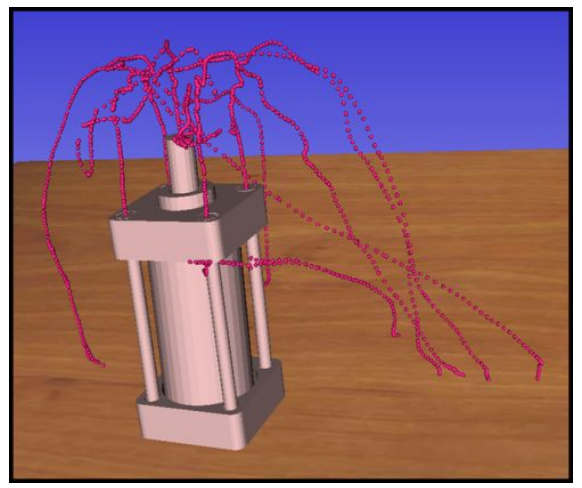

(b)

Figure 14. Visualization of the AS1 trajectories: a) cylinder assembly and b) complete assembly. 
The results evidence that AS1 needs only $67 \%$ of the energy (TAE) required by AS2. This performance is also observed in the TAEE metric, where the energy efficiencies of AS1 and AS2 are $38.8 \%$ and $28.8 \%$, respectively. These results are because in the AS2 the plunger is assembled before the cylinder, leading to eccentricity problems that cause interferences and require more manipulation movements during the cylinder assembly, as shown in Figure 15. In addition, the $P H$ and $E H T$ metrics for the cylinder are 1 and $19 \mathrm{~s}$ for AS1, respectively, and 7 and 47s for AS2, confirming that AS2 requires more grasping and manipulation operations than AS1.

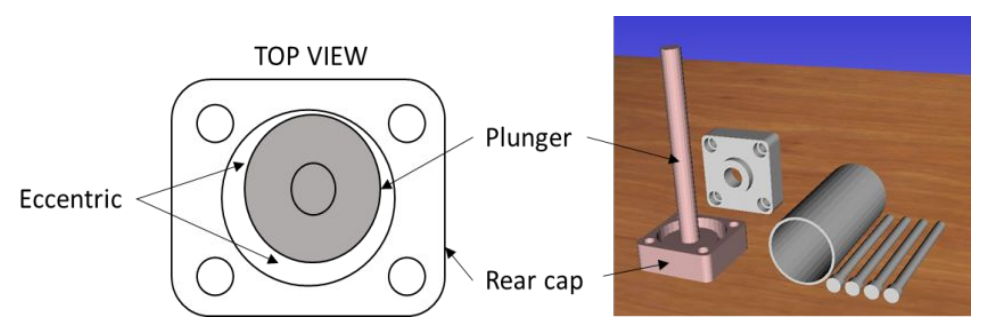

(a)

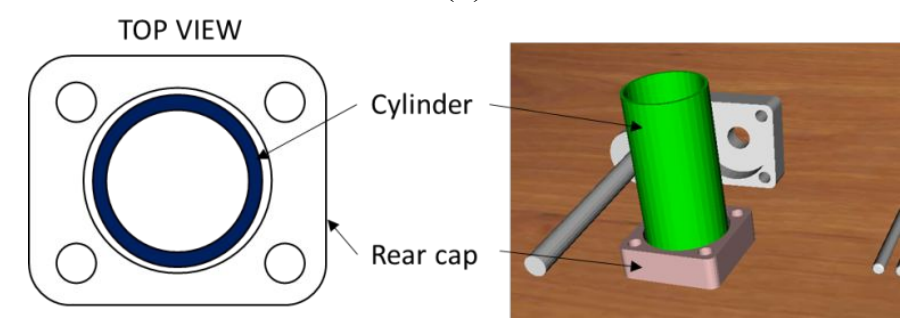

(b)

Figure 15. Cylinder assembly differences: a) AS2 and b) AS1.

Regarding part grasping (TAH), AS1 is better than AS2 since it requires only 16 grasping operations while AS2 requires 20 operations. This performance is also observed in the $H E$ values, being $50 \%$ for AS1 and $40 \%$ for AS2.

The results also shows that AS2 requires a smaller workspace (WS) volume (11 030.1 $\left.\mathrm{cm}^{3}\right)$ than AS1 $\left(12869.3 \mathrm{~cm}^{3}\right)$; being the main difference in the elevation. This $W S$ information is relevant for the assembly cell design and its integration into a production 
line (factory planning). In the case of robotic assembly, the information is useful to define the robot workspace.

Lastly, AS1 and AS2 are equally complex because both require an angular manipulability of $180^{\circ}$ around each coordinate axis $(A M)$ and 6 degrees of freedom $(D O F)$.

\section{Discussion}

The case study results have shown that the proposed haptic-enabled virtual approach is an effective tool to plan and objectively assess product assembly. The system is able to generate assembly plans from the VA execution. Moreover, by incorporating the experience of the specialist in the virtual assembly environment, the number of assembly plans to be generated and evaluated are reduced, and therefore the efficiency of the assembly planning process increases. The objective assessment of a product assembly is based on the quantification and comparison of new proposed assembly metrics, which are related to the assembly performance. These assembly metrics are automatically calculated from the information logged during the VA execution, and quantify the assembly performance in terms of time, distance, energy and efficiency.

Note that the values of the assembly metrics calculated from the virtual assembly information may differ from the values corresponding to the real assembly process; however, the behaviour and tendencies of the virtual and the real assembly tasks are the same (Gonzalez-Badillo et al., 2014; Gallegos-Nieto et al., 2017). Therefore, the VA evaluation is valid and useful, and the metrics can be adjusted to reproduce the real assembly values. Finally, it can be said that the proposed VA planning approach generates a large amount of technical data that can be used to support the decision-making process along the entire product life cycle, leading to time and cost reductions. 


\section{Conclusions}

A new method for the generation and objective evaluation of product assembly using virtual reality and haptics has been presented. The proposed method is based on the execution and data recording of the product assembly in a haptic-enabled virtual environment. For each completed assembly task, the system automatically generates the assembly plan and computes a set of assembly metrics, which are used to objectively evaluate the assembly strategies. The results have shown that the proposed approach is feasible, effective, and able to generate more useful and practical information than existing methods and systems. Moreover, the integration of haptics, physical-based behaviour, assembly logging, assembly metrics, and the experience and knowledge of the specialist, has led to a more intuitive, practical, objective and efficient assembly planning system.

\section{Acknowledgments}

The authors would like to thank the financial support from the National Science and Technology Council (CONACYT) of Mexico, grant number CB-2010-01-154430.

\section{References}

Adams, R. J., Klowden, D. and Hannaford, B. (2001), "Virtual training for a manual assembly task", Haptics-e, Vol. 2 No. 2, pp. 1-7.

Akpinar, S., Bayhan, G. M. and Baykasoglu, A. (2013), "Hybridizing ant colony optimization via genetic algorithms for mixed-model assembly line balancing problem with sequence dependent setup times between task", Applied Soft Computing, Vol. 13 No. 1 , pp. 574-589. 
Aleotti, J. and Caselli, S. (2011), "Physics-based virtual reality for task learning and intelligent disassembly planning", Virtual Reality, Vol. 15 No. 1, pp. 41-54.

Ben-Arieh, D., Rajeev, Ranjan Kumar and Tiwari, M. K. (2004), “Analysis of assembly operations' difficulty using enhanced expert high-level colored fuzzy petri net model”, Robotics and Computer-Integrated Manufacturing, Vol. 20 No. 5, pp. 385-403.

Bonneville, F., Perrard, C. and Henrioud, J. M. (1995), “A genetic algorithm to generate and evaluate assembly plans", Proceedings 1995 INRIA/IEEE Symposium on Emerging Technologies and Factory Automation. ETFA'95, Paris, France, 1995, Vol 2, pp. 231-239.

Boothroyd, G and Alting, L (1992), "Design for assembly and disassembly", CIRP annals - Manufacturing Technology, Vol. 41 No. 2, pp. 625-636.

Bordegoni, M., Cugini, U., Belluco, P. and Aliverti, M. (2009), "Evaluation of a hapticbased interaction system for virtual manual assembly", in Shumaker R. (Ed.) Virtual and Mixed Reality. Lecture Notes in Computer Science, Vol. 5622. Springer, Berlin, Heidelberg.

Boud, A. C., Baber, C. and Steiner, S. J. (2000), "Virtual reality: a tool for assembly?", Presence: Teleoperators and Virtual Environments, Vol. 9 No. 5, pp. 486-496.

Brough, J. E., Schwartz, M., Gupta, S. K., Anand, D. K., Kavetzky, R. and Pettersen, R. (2007), "Towards the development of a virtual environment-based training system for mechanical assembly operation", Virtual Reality, Vol. 11 No. 4, pp. 189-206.

De Fazio, T. L., et al. (1991) "A prototype of feature-based design for assembly", in Sriram D, Logcher R, Fukuda S (Ed.) Computer-Aided Cooperative Product Development, WCACPD 1989, Lecture Notes in Computer Science, Vol. 492. Springer, Berlin, Heidelberg. 
Chen, C., Hu, H. (2018) "Liveness-Enforcing Supervision in AMS-Oriented HAMGs: An Approach Based on New Characterization of Siphons Using Petri Nets", IEEE Transactions on Automatic Control, Vol. 63, pp. 1987-2002.

Fletcher, C. A., Ritchie, J. M., and Lim, T. (2012), "The generation of machining process plans using a haptic virtual reality system", Proceedings of the ASME 2012 International Design Engineering Technical Conference \& Computers and Information in Engineering Conference, pp. 231-236.

Gallegos-Nieto, E., Medellín-Castillo, H. I., González-Badillo, G., Lim, T. and Ritchie, J. (2017), "The analysis and evaluation of the influence of haptic-enabled virtual assembly training on real assembly performance", International Journal of Advanced Manufacturing Technology, Vol. 89 No. 1, pp. 581-598.

Gao, W., Shao, X. and Liu, H. (2014), "Virtual assembly planning and assembly-oriented quantitative evaluation of product assemblability", International Journal of Advanced Manufacturing Technology, Vol. 71 No. 1, pp. 483-496.

Garbaya, S., Romano, D. and Hattar, G. (2019), "Gamification of assembly planning in virtual environment", Assembly Automation, Vol. 39 No. 5, pp. 932-943.

Garbaya, S. and Zaldivar-Colado, U. (2007), "The affect of contact force sensations on user performance in virtual assembly tasks", Virtual Reality, Vol. 11 No. 4, pp. 287299.

Goldwasser, M., Latombe, J. and Motwani, R. (1999), “Complexity measures for assembly sequences", International Journal of Computational Geometry and Applications, Vol. 9 No. 4-5, pp. 371-417.

Gonzalez-Badillo, G., Medellin-Castillo, H. I., Lim, T., Ritchie, J. M. and Garbaya, S. (2014), "The development of a physics and constraint based haptic virtual assembly system”, Assembly Automation, Vol. 34 No. 1, pp. 41-55. 
Hassan, S. and Yoo, J. (2010), "Haptic guided optimized aircraft maintenance assembly disassembly path planning scheme", International Conference on Control Automation and Systems (ICCAS), Gyeonggi-do, 2010, pp. 1667-1672.

Homem de Mello, L. S. and Sanderson, A. C. (1991) “A correct and complete algorithm for the generation of mechanical assembly sequence", IEEE Transactions on Robotics and Automation, Vol. 7 No. 2, pp. 228-240.

Hu, H. and Liu, Y. (2015), "Supervisor synthesis and performance improvement for automated manufacturing systems by using petri nets", IEEE Transactions on Industrial Informatics, Vol. 11 No. 2, pp. 450-458.

Hui, W., Dong, X. and Guanghong, D. (2006), “A new heuristic method for assembly planning", Computational Engineering in Systems Applications, IMACS Multiconference on, 2006.

Jayaram, S., Jayaram, U., Kim, Y. J., DeChenne, C., Lyons, K. W., Palmer, C. and Mitsui, T. (2007), "Industry case studies in the use of immersive virtual assembly", Virtual Reality, Vol. 11 No. 4, pp. 217-228.

Jayasekera, R. D. M. D. \& Xu, X. (2019), “Assembly validation in virtual reality-a demonstrative case", The International Journal of Advanced Manufacturing Technology, pp. 1-14. https://doi.org/10.1007/s00170-019-03795-y

Jia, D., Bhatti, A. and Nahavandi, S. (2009), "Design and evaluation of a haptically enable virtual environment for object assembly training", in IEEE International Workshop on Haptic Audio visual Environments and Games, Lecco, 2009, pp. 75-80.

Li, J., Xu, Y., Ni, J. and Wang Q. (2016), "Glove-based virtual hand grasping for virtual mechanical assembly", Assembly Automation, Vol. 36 No. 4, pp. 349-361.

Liu, K., Yin, X., Fan, X. and He, S. (2015), "Virtual assembly with physical information: a review", Assembly Automation, Vol. 35 No. 3, pp. 206-220. 
Lv, H. and Lu, C. (2010), “An assembly sequence planning approach with a discrete particle swarm optimization algorithm", Int J Adv Manuf Technol. Vol. 50 No. 5, pp. 761-770.

Ladeveze, N., Fourquet, J. and Puel, B. (2010), "Interactive path planning for haptic assistance in assembly tasks", Computers and Graphics, Vol. 34 No. 1, pp. 17-25.

Marian, R. M., Luong, L. H. S. and Abhary, K. (2006), "A genetic algorithm for the optimisation of assembly sequences", Computers and Industrial Engineering, Vol. 50 No. 4 , pp. 503-527.

Medellin, Hugo, Corney, Jonathan, Ritchie, James and Lim, Theodore (2010) “Automatic generation of robot and manual assembly plans", Assembly Automation, Vol. 30 No. 2, pp. 173-183.

Seth, A., Su, H. and Vance, J. M. (2006), "SHARP: A system for haptic assembly and realistic prototyping", in ASME International Design Engineering Technical Conferences and Computers and Information in Engineering Conference, 26th Computers and Information in Engineering Conference, Vol. 3, pp. 905-912.

Seth, A., Vance, J. M. and Oliver, J. H. (2011), "Virtual reality for assembly methods prototyping: a review", Virtual Reality, Vol. 15 No. 1, pp. 5-20.

Sinanoglu, C. and Borklu, H. R. (2005), “An assembly sequence-planning system for mechanical parts using neutral network", Assembly automation, Vol. 25 No. 1, pp. 3852.

Thornton, J. (2009), “At Ford, Ergonomics Meets Immersive Engineering”, available at: https://www.ehstoday.com/health/ergonomics/ford-ergonomics-simulation-0409 (Accessed 05 March 2019).

Vo, D. M., Vance, J. M. and Marasinghe, M. G. (2009), “Assessment of haptics-bases interaction for assembly tasks in virtual reality", World Haptics 2009 - Third Joint 
EuroHaptics conference and Symposium on Haptic Interfaces for Virtual Environment and Teleoperator Systems, pp. 494-499.

Wang, H, Xiand, D, Rong, Y and Zhang, L (2013) “Intelligent disassembly planning: its fundamental methodology", Assembly Automation, Vo. 33 No. 1, pp. 78-85.

Xia, P., Lopes, A. M. and Restivo, M. T. (2011), "Design and implementation of a hapticbased virtual assembly system”, Assembly Automation, Vol 31 No. 4, pp. 369-384.

Xia, P., Lopes, A. M. and Restivo, M. T. (2013), “A review of virtual reality and haptics for product assembly (part 1): rigid parts”, Assembly Automation, Vol. 33 No. 1, pp. $68-77$.

Yang, Y. and Hu, H. (2018), "A Distributed Control Approach to Automated Manufacturing Systems With Complex Routes and Operations Using Petri Nets", IEEE Transactions on Systems, Man, and Cybernetics: Systems, pp. 1-15.

Yoo, C. J. (2011), “Assembly simulations in virtual environments with optimized haptic path and sequence", Robotics and Computer-Integrated Manufacturing, Vol. 27 No. 2, pp. 306-317.

Yusof, Y. and Latif, K. (2013), “Computer aided process planning: A comprehensive survey", Advance in Sustainable and Competitive Manufacturing Systems. Lecture Notes in Mechanical Engineering, Springer, Heidelberg, pp. 389-400. 


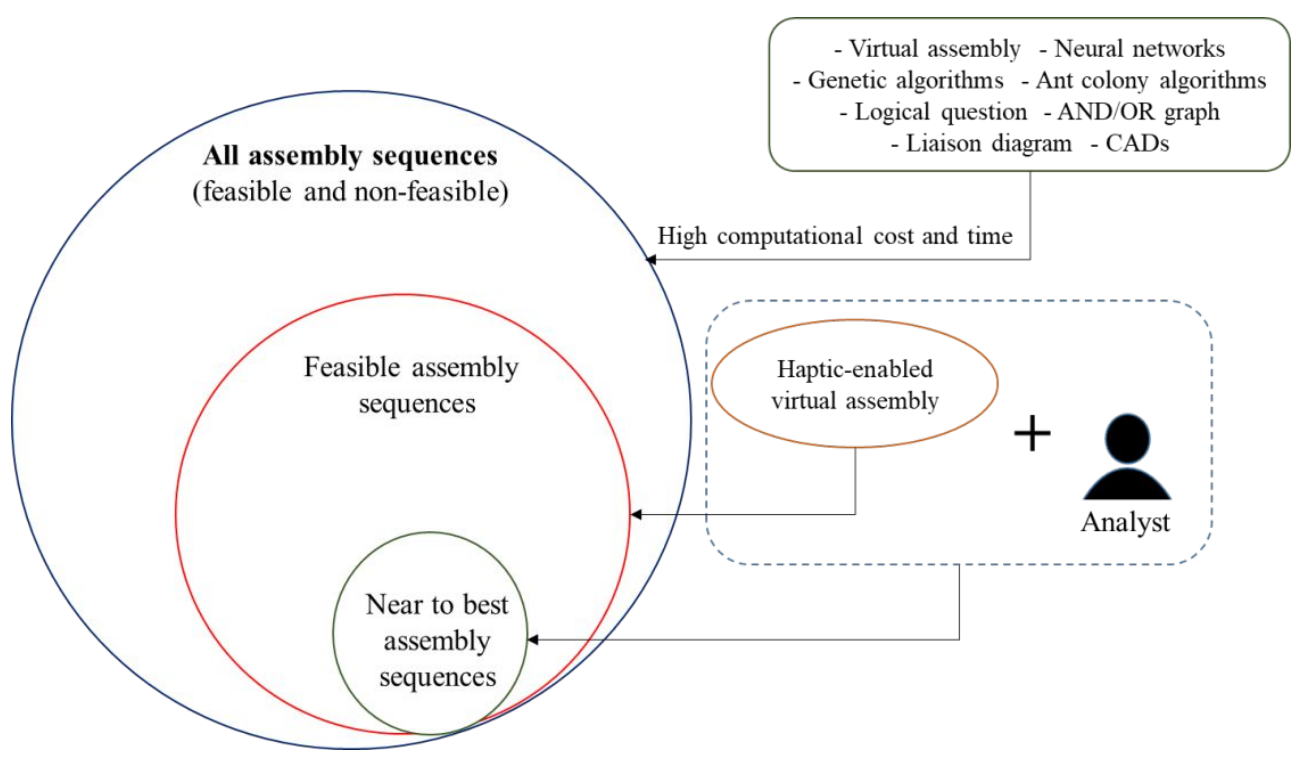

Figure 1. Haptic-enabled VA planning vs. other assembly planning methods. 


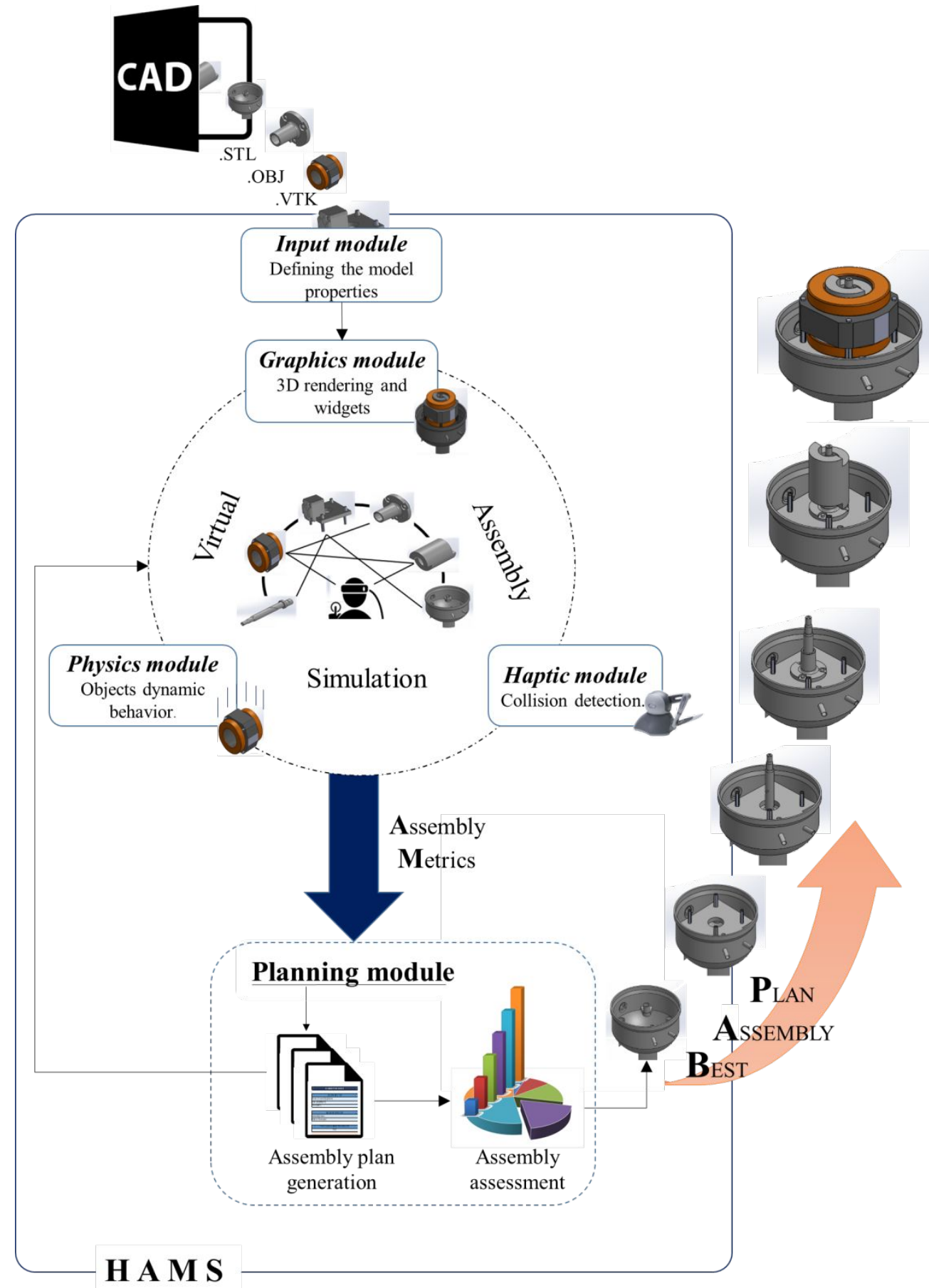

Figure 2. HAMS architecture. 


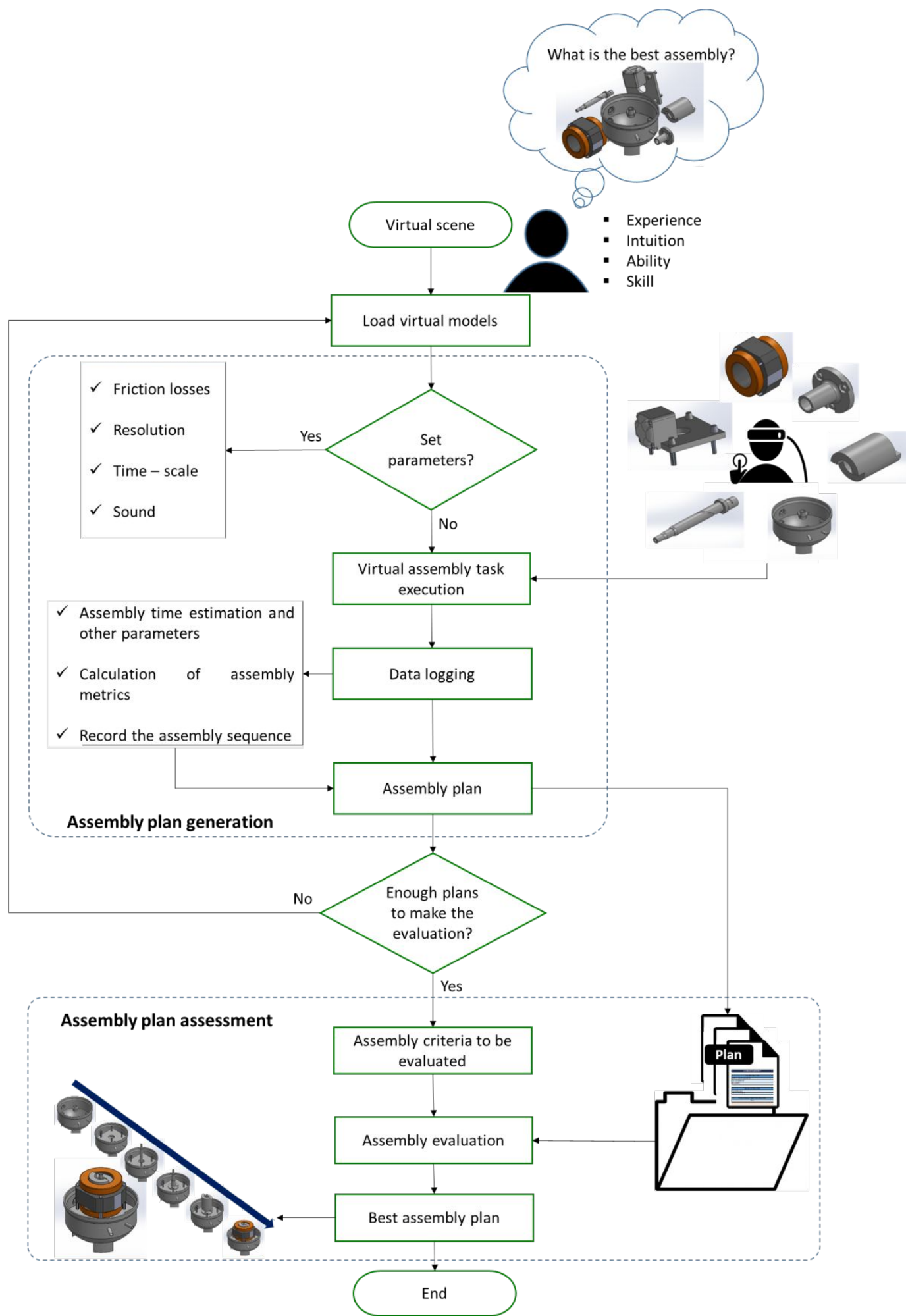

Figure 3. Assembly planning procedure. 


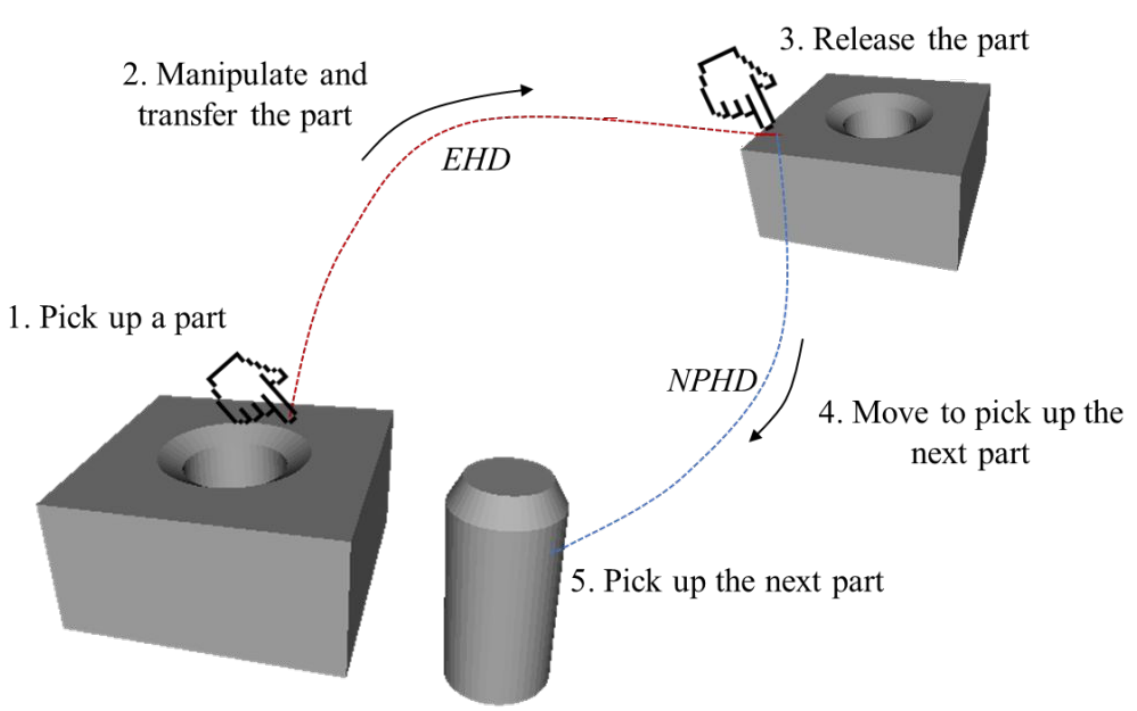

Figure 4. Distance concepts involved in the VA.

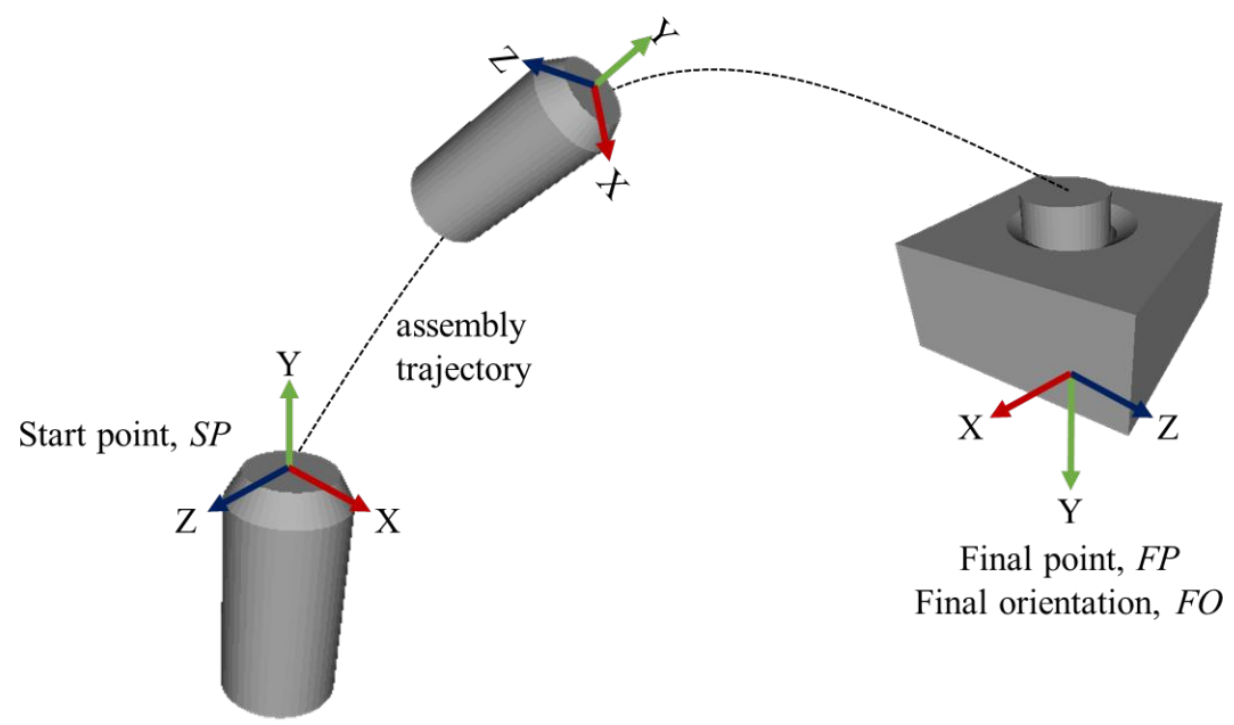

Figure 5. Initial and final configuration of a part. 


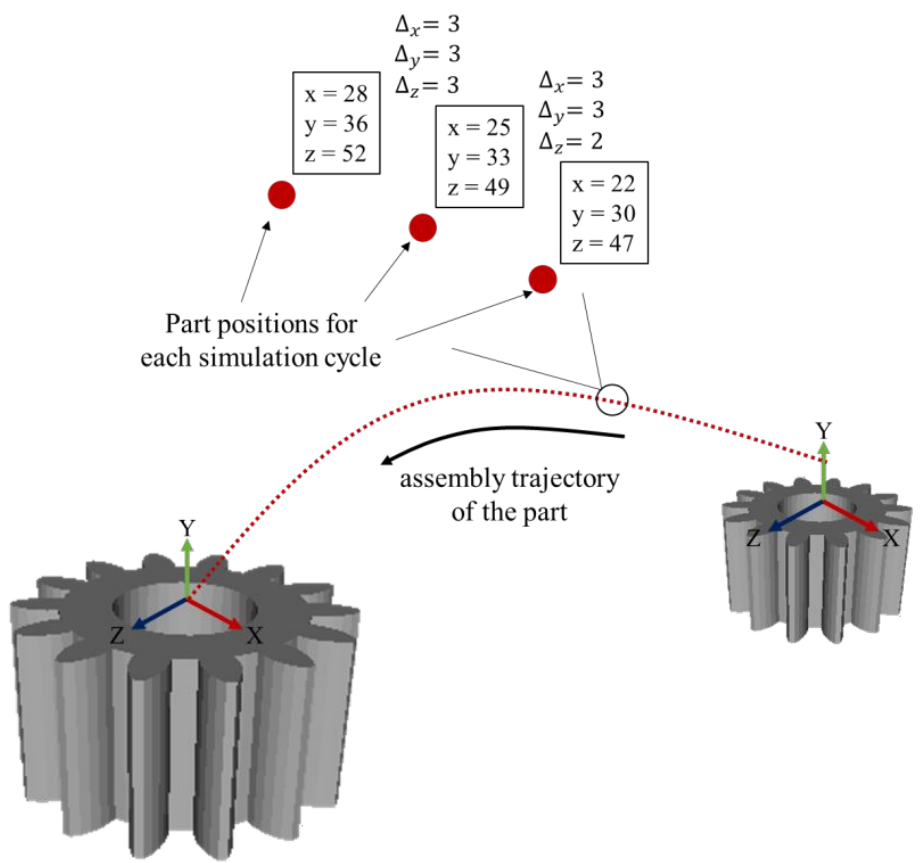

Figure 6. Displacements comprising a virtual assembly path.

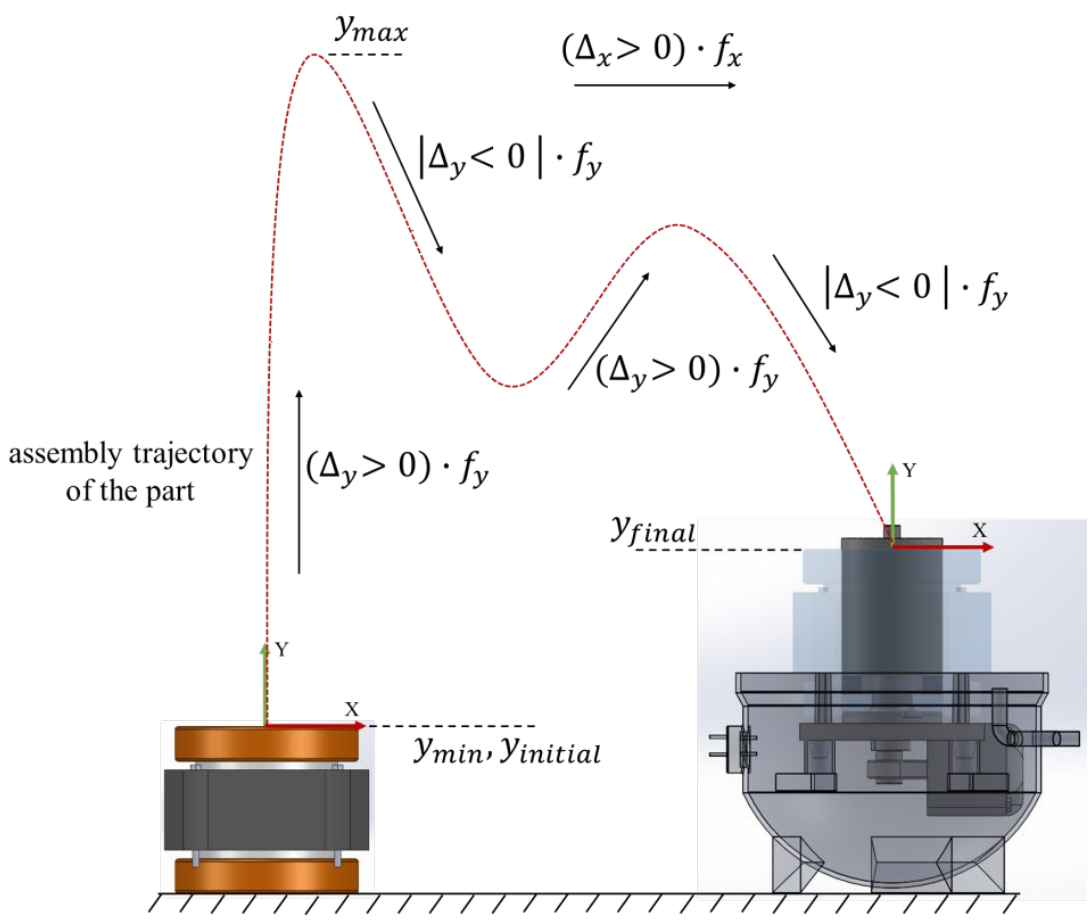

Figure 7. Energy concepts when moving a part. 


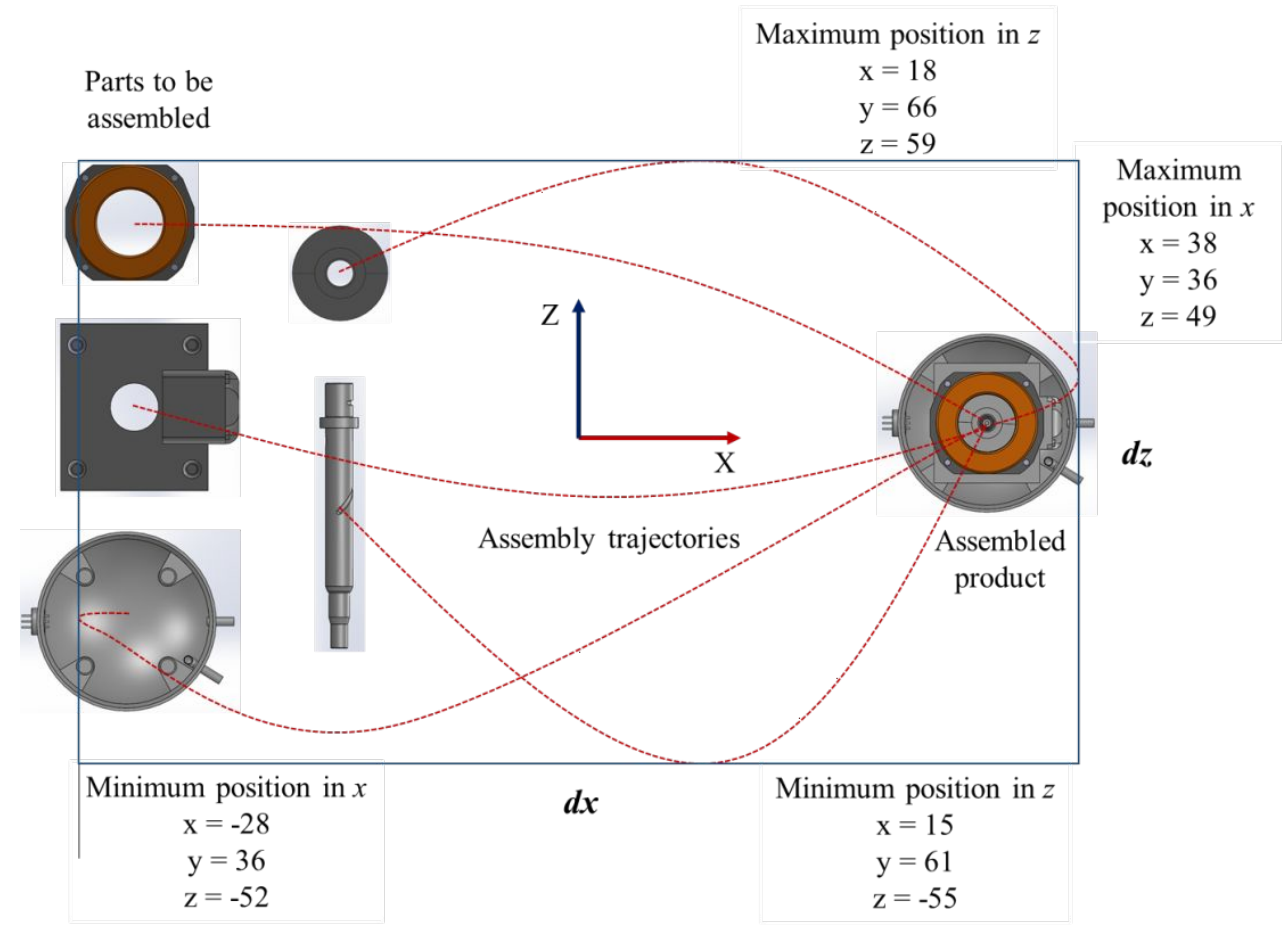

Figure 8. Representation of the virtual workspace.

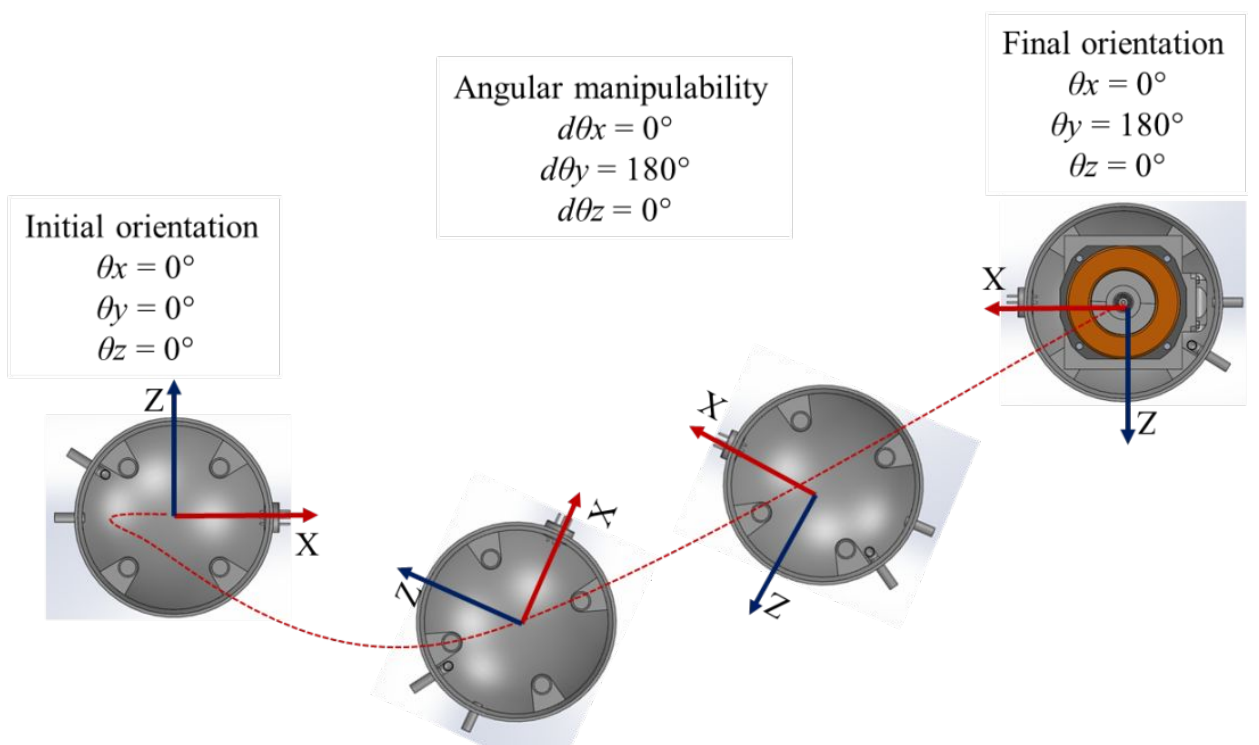

Figure 9. Representation of the assembly manipulability concept. 


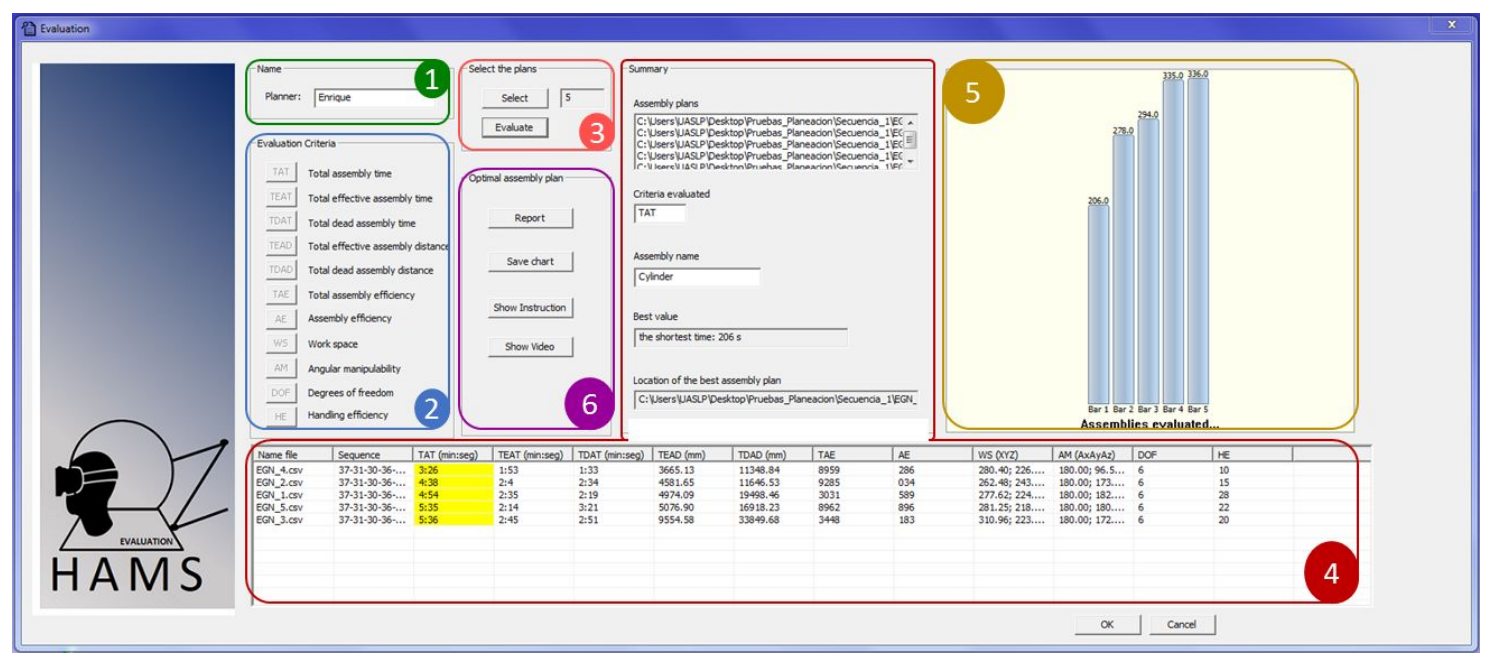

Figure 10. Assembly plan assessment GUI.

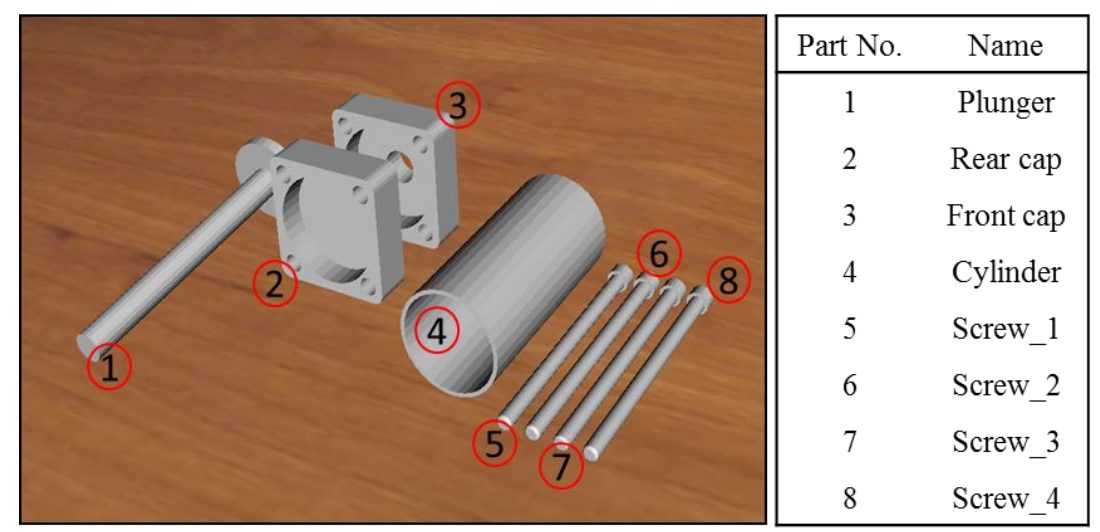

Figure 11. Linear actuator virtual assembly task loaded into HAMS.

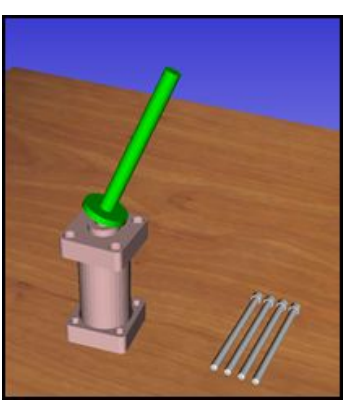

(a)

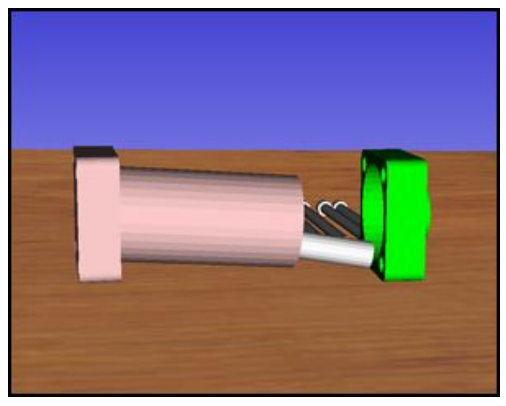

(b)

Figure 12. Non-feasible assembly sequences: a) accessibility problem and b) stability problem. 


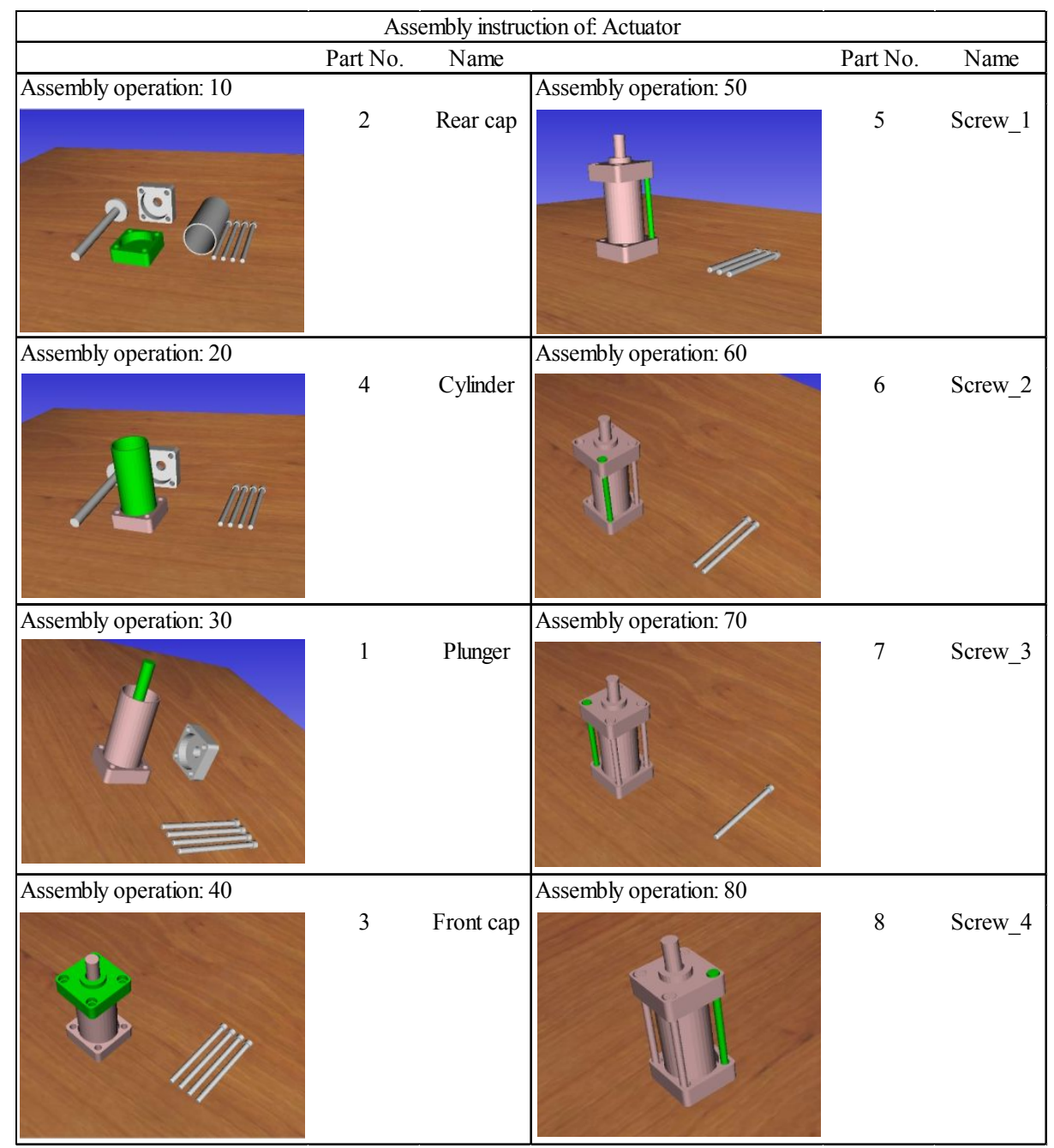

Figure 13. Assembly instructions corresponding to AS1.

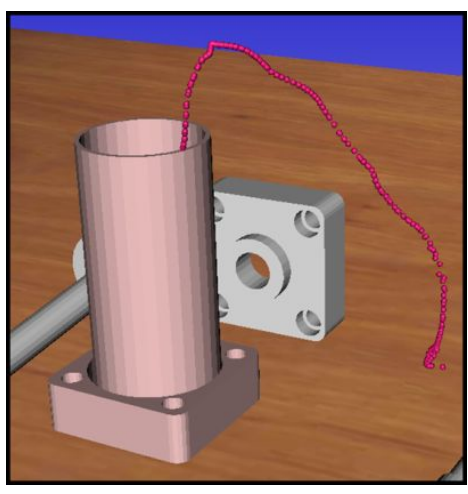

(a)

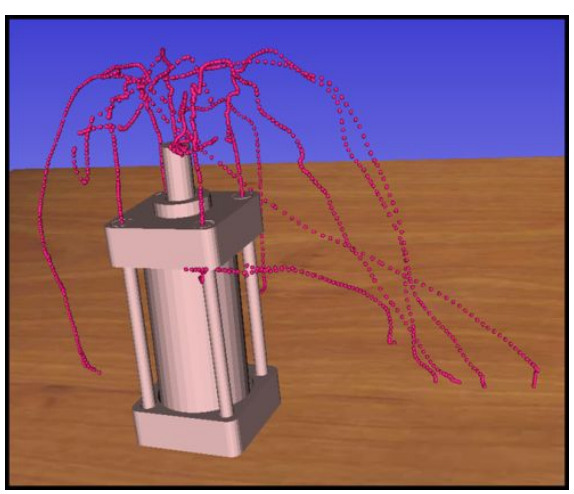

(b)

Figure 14. Visualization of the AS1 trajectories: a) cylinder assembly and b) complete assembly. 


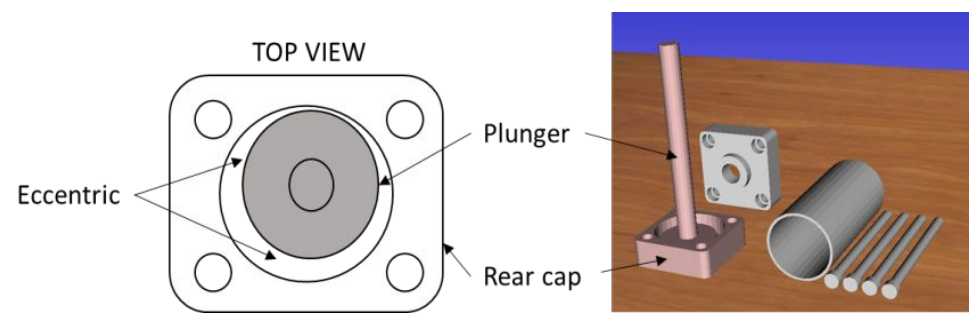

(a)

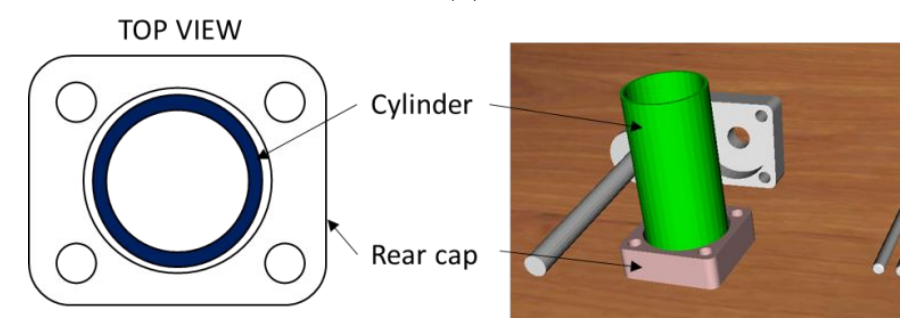

(b)

Figure 15. Cylinder assembly differences: a) AS2 and b) AS1. 
Table 1 . VA systems for assembly planning.

\begin{tabular}{|c|c|c|c|c|c|c|c|c|c|c|}
\hline & \multirow{2}{*}{ VA system } & \multirow[b]{2}{*}{$\begin{array}{c}\text { System } \\
\text { evaluation }\end{array}$} & \multirow[b]{2}{*}{$\begin{array}{l}\text { Sequence } \\
\text { generation }\end{array}$} & \multicolumn{4}{|c|}{ Assembly metrics } & \multicolumn{3}{|c|}{ Assembly planning } \\
\hline & & & & $\stackrel{\ominus}{\ominus}$ & 台 & 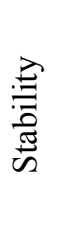 & 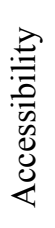 & 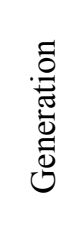 & 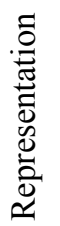 & 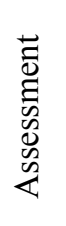 \\
\hline \multirow{12}{*}{ 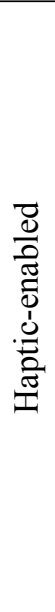 } & Xia et al., 2011 & $\mathrm{x}$ & & $\mathrm{x}$ & & & $\mathrm{x}$ & & & \\
\hline & Thing et al., 2010 & $\mathrm{x}$ & & $\mathrm{x}$ & & & $\mathrm{x}$ & & & \\
\hline & Bordegoni et al., 2009 & $\mathrm{x}$ & & $\mathrm{x}$ & & & $\mathrm{x}$ & & & \\
\hline & Vo et al., 2009 & $\mathrm{x}$ & & $\mathrm{x}$ & & & $\mathrm{x}$ & & & \\
\hline & Garbaya et al., 2007 & $\mathrm{x}$ & & $\mathrm{x}$ & & & $\mathrm{x}$ & & & \\
\hline & Adams et al., 2001 & $\mathrm{x}$ & & $\mathrm{x}$ & & & $\mathrm{x}$ & & & \\
\hline & Yoo, 2011 & $\mathrm{x}$ & & $\mathrm{x}$ & $\mathrm{x}$ & & $\mathrm{x}$ & & & $x^{1}$ \\
\hline & Seth et al., 2006 & $\mathrm{x}$ & & $\mathrm{x}$ & & & $\mathrm{x}$ & & & $x^{2}$ \\
\hline & Jia et al., 2009 & $\mathrm{x}$ & & $\mathrm{x}$ & & & $\mathrm{x}$ & & & \\
\hline & Ladeveze et al., 2010 & $\mathrm{x}$ & & $\mathrm{x}$ & & & $\mathrm{x}$ & & & \\
\hline & Hassan et al., 2010 & $\mathrm{x}$ & & & & & $\mathrm{x}$ & & & $\mathrm{x}^{3}$ \\
\hline & Gonzalez et al., 2014 & $\mathrm{x}$ & $\mathrm{x}$ & $\mathrm{x}$ & & $\mathrm{x}$ & $\mathrm{x}$ & $\mathrm{x}$ & $\mathrm{x}$ & \\
\hline \multirow{8}{*}{ 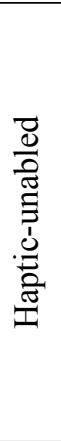 } & Boud et al., 2000 & $\mathrm{x}$ & & $\mathrm{x}$ & & & $\mathrm{x}$ & & & \\
\hline & Brough et al., 2007 & $\mathrm{x}$ & & $\mathrm{x}$ & & & & & & \\
\hline & Jayaram et al., 2007 & $\mathrm{x}$ & $\mathrm{x}$ & & & & & & & \\
\hline & Aleotti et al., 2011 & $\mathrm{x}$ & & $\mathrm{x}$ & & $\mathrm{x}$ & $\mathrm{x}$ & & & \\
\hline & Gao et al., 2014 & $\mathrm{x}$ & & $\mathrm{x}$ & $\mathrm{x}$ & $\mathrm{x}$ & $\mathrm{x}$ & & & \\
\hline & Li et al., 2016 & $\mathrm{x}$ & $\mathrm{x}$ & & & & $\mathrm{x}$ & & & \\
\hline & Garbaya et al., 2019 & $\mathrm{x}$ & $\mathrm{x}$ & & & & & $\mathrm{x}$ & & \\
\hline & $\begin{array}{l}\text { Jayasekera \& Xu, } \\
2019\end{array}$ & $\mathrm{x}$ & & & $\mathrm{x}$ & & $\mathrm{x}$ & & & \\
\hline
\end{tabular}




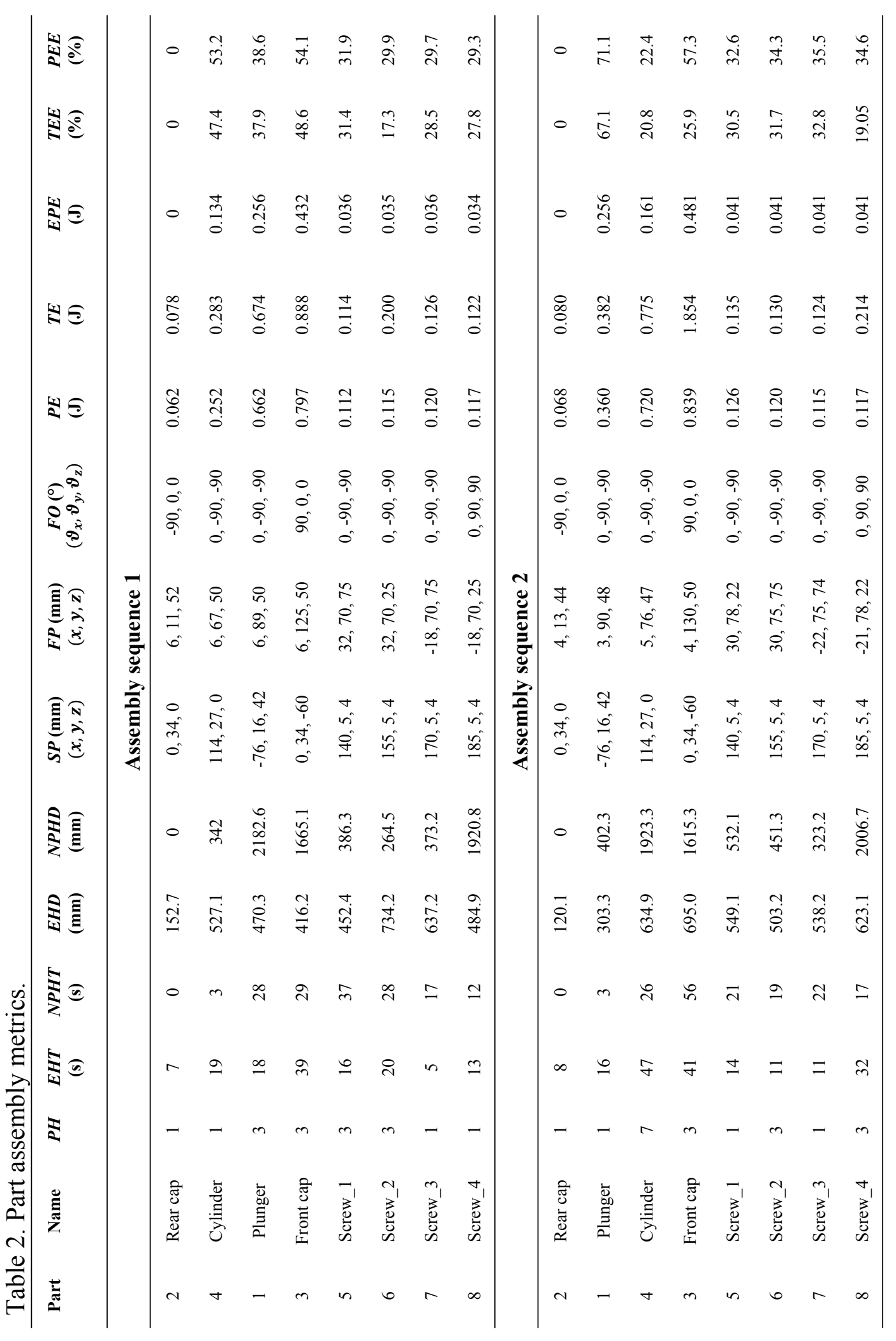


Table 3. Task assembly metrics.

\begin{tabular}{cll}
\hline Assembly metric & \multicolumn{1}{c}{ Assembly sequence 1 } & Assembly sequence 2 \\
\hline$E T C T$ & $137 \mathrm{~s}$ & $180 \mathrm{~s}$ \\
$N P T C T$ & $154 \mathrm{~s}$ & $164 \mathrm{~s}$ \\
$T C T$ & $291 \mathrm{~s}$ & $344 \mathrm{~s}$ \\
$E A D$ & $3875 \mathrm{~mm}$ & $3966 \mathrm{~mm}$ \\
$N P A D$ & $7134 \mathrm{~mm}$ & $7254 \mathrm{~mm}$ \\
$T A D$ & $11009 \mathrm{~mm}$ & $11220 \mathrm{~mm}$ \\
$T A E$ & $2.485 \mathrm{~J}$ & $3.694 \mathrm{~J}$ \\
$T A E E$ & $38.75 \%$ & $28.8 \%$ \\
$A P E E$ & $43.04 \%$ & $43.08 \%$ \\
$W S$ & $(277.6,224.5,206.5) \mathrm{mm}$ & $(263.2,221.5,189.2) \mathrm{mm}$ \\
$A M$ & $\theta_{x}=180^{\circ}, \theta_{y}=180^{\circ}, \theta_{z}=180^{\circ}$ & $\theta_{x}=180^{\circ}, \theta_{y}=180^{\circ}, \theta_{z}=180^{\circ}$ \\
$D O F$ & 6 & 6 \\
$T A H$ & 16 & 20 \\
$H E$ & $50 \%$ & $40 \%$ \\
\hline
\end{tabular}




\section{Manuscript: AA-10-2019-0169R2 Haptic-enabled virtual planning and assessment of product assembly}

The authors would like to thank the editor for the work and comments provided in order to improve the quality of the manuscript before its publication. The manuscript has been revised and the following changes have been made. Major changes have been highlighted as red text in the document.

\section{Response to Editor's comments}

1. Before we proceed to publication I would like to invite you to read the attached draft guidelines for authors 'How to publish in Assembly Automation'. Our aim is to help you maximise the impact of your manuscript so that it is as widely downloaded and cited as possible.

R: The guidelines "How to publish in Assembly Automation" were carefully reviewed and the manuscript was modified according to them.

2. At this stage the most appropriate section of the attached guide is 'Pre-accept' and under this heading I would like you to improve/correct the following aspects:

Format

English grammar

References

Figures

Figure copyright

Video abstracts

$R$ : The entire paper has been formatted according to the provided guide. The English grammar has been also carefully revised. All references have been formatted according to the Harvard style and checked for completeness, accuracy and consistency. Figures have been also revised and none of them requires copyright since the authors created all figures.

3. Please also consider the comments under 'How to submit a Manuscript' that relate to the title and structured abstract. I am not suggesting that you should change them - just that you consider if they could be further optimised.

$R$ : The title of the paper has been revised and modified to eight words. The structured abstract was also revised and modified to remove the use of personal pronouns within the structured abstract and body of the paper.

Once again, the authors greatly appreciate the valuable comments provide by the editor. We believe that the quality of the revised manuscript has been largely improved. 